The supporting information of the article entitled:

\title{
Structure-Based Discovery of SD-36 as a Potent, Selective and Efficacious PROTAC Degrader of STAT3 Protein
}

\author{
Haibin Zhou, ${ }^{\dagger+ \pm}$ Longchuan Bai, ${ }^{\dagger+ \pm}$ Renqi $\mathrm{Xu}^{\dagger+ \pm}$, Yujun Zhao ${ }^{\dagger+ \pm}$, Jianyong Chen ${ }^{\dagger+ \pm}$, Donna \\ McEachern $^{\dagger+}$, Krishnapriya Chinnaswamy ${ }^{\#}$, Bo Wen $\nabla$, Chao-Yie Yang ${ }^{\dagger+}$, Zhaomin Liu $^{\dagger+}$, Mi \\ Wang $^{\dagger^{+}}$, Liu Liu ${ }^{\dagger+}$, Jennifer L. Meagher ${ }^{\#}$, Duxin Sun $\nabla$, Jeanne A. Stuckey ${ }^{\#}$, and Shaomeng \\ Wang $^{\dagger+\Phi \S *}$ \\ ${ }^{\dagger}$ Rogel Cancer Center, Departments of ${ }^{+}$Internal Medicine and Pharmacology, Medical School, \\ ${ }^{\S}$ Medicinal Chemistry, College of Pharmacy, ${ }^{\#}$ Life Sciences Institute, $\nabla$ Department of \\ Pharmaceutical Sciences, College of Pharmacy, University of Michigan, Ann Arbor, Michigan \\ 48109, United States
}

\section{Contents}

FP assay for the binding of STAT3 SH2 domain inhibitors (Figure S1) ................................S2

Binding affinities of the STAT3 inhibitors (Table S1) …................................................... 3

Computational model of compound 4 in complex with STAT3 (Figure S2) ...........................S4

Crystallography Data Collection and Refinement Statistics (Table S2) ...............................S5

Western blotting analysis of total STAT3 and p-STAT3 ${ }^{\mathrm{Y} 705}$ proteins (Figures S3-9)......S6-S12

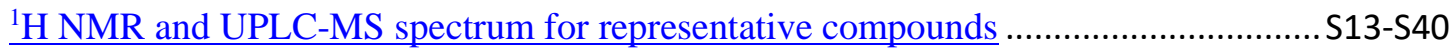


A

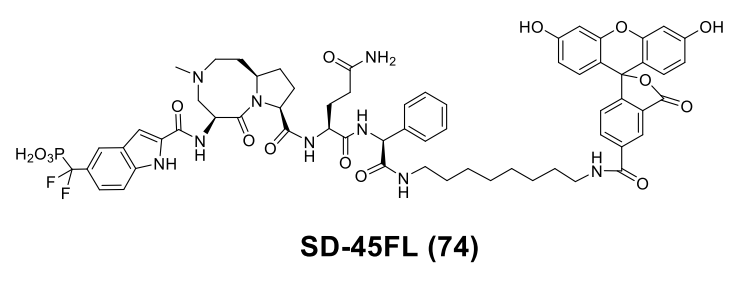

C $\quad$\begin{tabular}{|c|c|c|c|c|}
\hline & SI-109 & 9 & 10 & 11 \\
\hline $\mathrm{IC} 50$ & 0.04402 & 0.09185 & 1.499 & 0.4767 \\
\hline
\end{tabular}

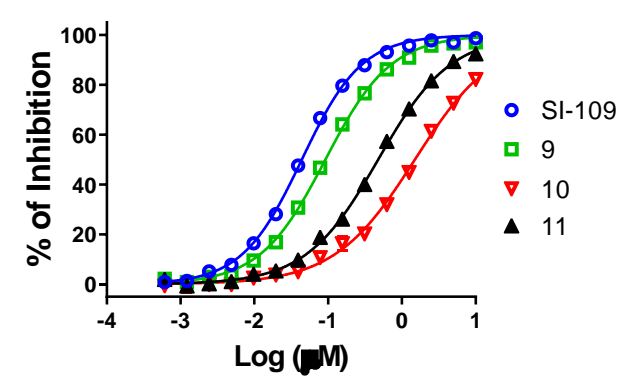

B

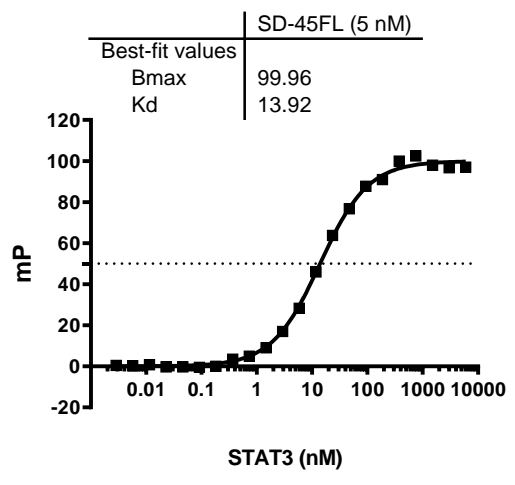

Figure S1. FP assay for the binding of STAT3 SH2 domain inhibitors to purified recombinant STAT3 protein. (A). Fluorescently labeled compound SD-45FL. (B). Binding isotherm of SD-45FL to STAT3. Fluorescence polarization (FP) saturation binding curve of SD45FL $(5 \mathrm{nM})$ incubated with serial diluted recombinant STAT3 $(0.006$ to $6 \mu \mathrm{M})$. The data are normalized to the highest value for each experiment. The estimated $\mathrm{Kd}$ is shown. One representative saturation curve is shown. (C). Competitive binding curves and $\mathrm{IC}_{50}$ values of compounds SI-109, 9, 10 and $\mathbf{1 1}$ to STAT3 as determined using the FP-based binding assay. 
Table S1. Binding affinities of previously reported compound CJ-887 and new STAT3 SH2 inhibitors in a competitive FP-based binding assay.

\begin{tabular}{|c|c|c|}
\hline $\mathbf{C m p d s}$ & $\mathbf{I C}_{\mathbf{5 0}}(\mathbf{n M})$ & $\boldsymbol{K}_{\mathbf{i}}(\mathbf{n M})$ \\
\hline $\mathbf{1}(\mathrm{CJ}-887)$ & $240 \pm 12$ & $47 \pm 35$ \\
\hline $\mathbf{2}$ & $105 \pm 5$ & $25 \pm 13$ \\
\hline $\mathbf{3}$ & $2809 \pm 155$ & $761 \pm 230$ \\
\hline $\mathbf{4}$ & $20 \pm 1$ & $7 \pm 1$ \\
\hline $\mathbf{5}$ & $44 \pm 11$ & $14 \pm 3$ \\
\hline $\mathbf{6}$ & $40 \pm 0$ & $14 \pm 0$ \\
\hline $\mathbf{7}$ & $34 \pm 1$ & $12 \pm 1$ \\
\hline $\mathbf{S I - 1 0 9}(\mathbf{8})$ & $42 \pm 15$ & $14 \pm 4$ \\
\hline $\mathbf{9}$ & $92 \pm 12$ & $33 \pm 5$ \\
\hline $\mathbf{1 0}$ & $1628 \pm 112$ & $584 \pm 40$ \\
\hline $\mathbf{1 1}$ & $459 \pm 82$ & $164 \pm 30$ \\
\hline
\end{tabular}




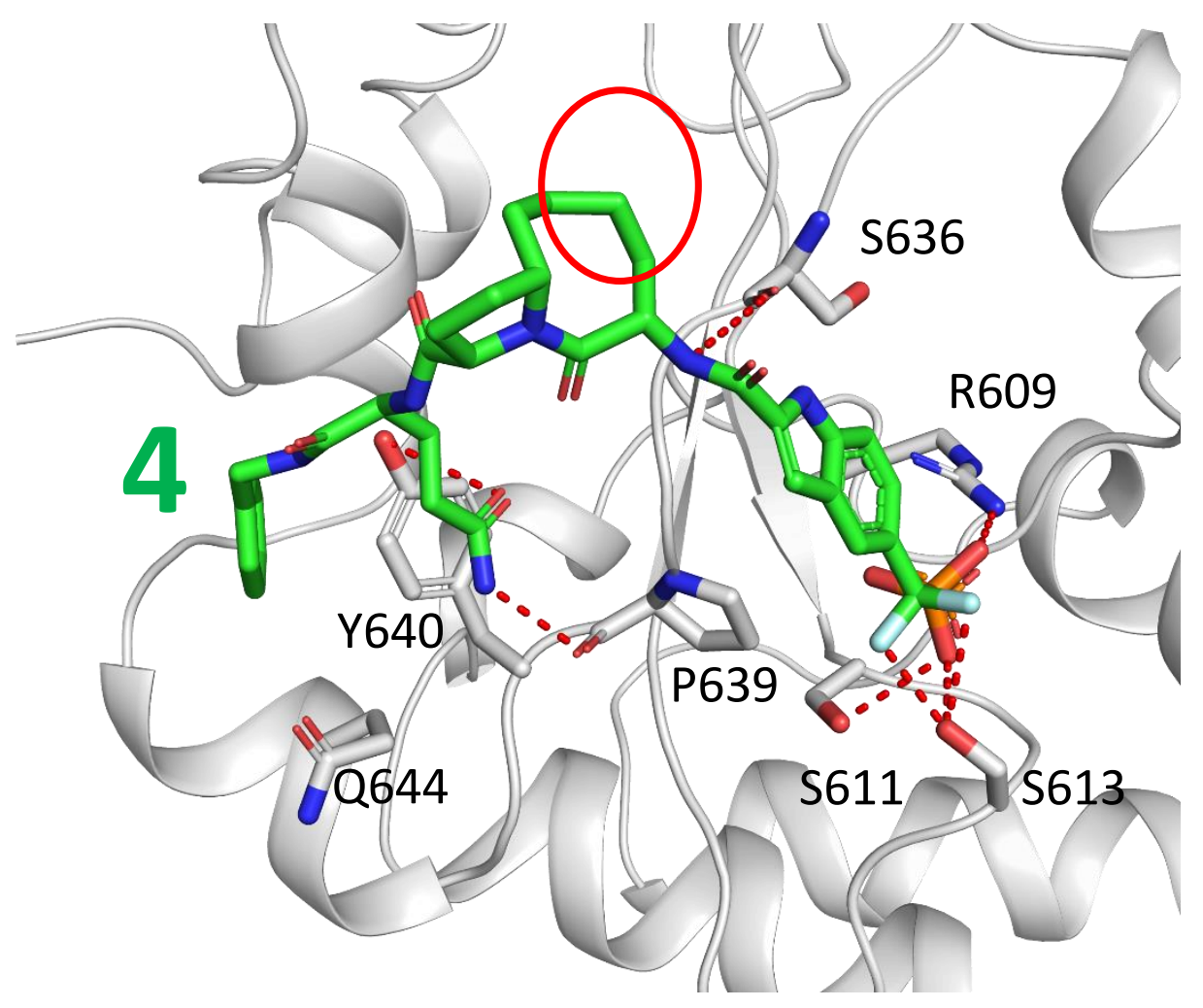

Figure S2. Computational model of compound 4 in complex with STAT3. 
Table S2. Crystallography Data Collection and Refinement Statistics

\begin{tabular}{|c|c|}
\hline Data Collection & STAT3-SI109 \\
\hline PDBID & 6NUQ \\
\hline Space Group & $P 4{ }_{1} 212$ \\
\hline Unit Cell (Å) & 84.1984 .19206 .37 \\
\hline Wavelength $(\AA)$ & 1.07812 \\
\hline Resolution $(\AA)^{1}$ & $3.15(3.2-3.15)$ \\
\hline Rsym $^{2}$ & $0.109(0.746)$ \\
\hline$<|/ \sigma|>^{3}$ & $2(10)$ \\
\hline Completeness $(\%)^{4}$ & $94.9(100)$ \\
\hline Redundancy & $11.9(12.0)$ \\
\hline \multicolumn{2}{|l|}{ Refinement } \\
\hline Resolution $(\AA ̊)$ & 3.15 \\
\hline R-Factor ${ }^{5}$ & 0.233 \\
\hline Rfree $^{6}$ & 0.260 \\
\hline Protein atoms & 4126 \\
\hline Ligands & 1 \\
\hline Water Molecules & 26 \\
\hline Unique Reflections & 12837 \\
\hline \multicolumn{2}{|l|}{ R.m.s.d. ${ }^{7}$} \\
\hline Bonds & 0.008 \\
\hline Angles & 0.99 \\
\hline MolProbity Score ${ }^{8}$ & 1.51 \\
\hline Clash Score ${ }^{8}$ & 2.67 \\
\hline $\mathrm{RSCC}^{9}$ & 0.92 \\
\hline $\mathrm{RSR}^{9}$ & 0.20 \\
\hline
\end{tabular}

${ }^{1}$ Statistics for highest resolution bin of reflections in parentheses.

${ }^{2} R_{s y m}=\Sigma_{h} \Sigma_{j}\left|I_{h j}<l_{h}>\right| / \Sigma_{h} \Sigma_{j} h_{h j}$, where $I_{h j}$ is the intensity of observation $j$ of reflection $h$ and $\left\langle I_{h}\right\rangle$ is the mean intensity for multiply recorded reflections.

Intensity signal-to-noise ratio.

${ }^{4}$ Completeness of the unique diffraction data.

${ }^{5} \mathrm{R}$-factor $=\Sigma_{\mathrm{h}}\left|\mathrm{IF}_{\mathrm{o}}\right|-\left|\mathrm{F}_{\mathrm{c}}\right|\left|/ \Sigma_{\mathrm{h}}\right| \mathrm{F}_{\mathrm{o}} \mid$, where $\mathrm{F}_{\mathrm{o}}$ and $\mathrm{F}_{\mathrm{c}}$ are the observed and calculated structure factor amplitudes for reflection $\mathrm{h}$.

${ }^{6} \mathrm{R}_{\text {free }}$ is calculated against a $5 \%$ random sampling of the reflections that were removed before structure refinement.

${ }^{7}$ Root mean square deviation of bond lengths and bond angles.

${ }^{8}$ Chen et al. (2010) MolProbity: all-atom structure validation for macromolecular crystallography. Acta Crystallographica D66:12-21.

${ }^{9}$ wwPDB Validation Server. 
A

STAT3 p-STAT3 ${ }^{Y 705}$

$\beta$-actin

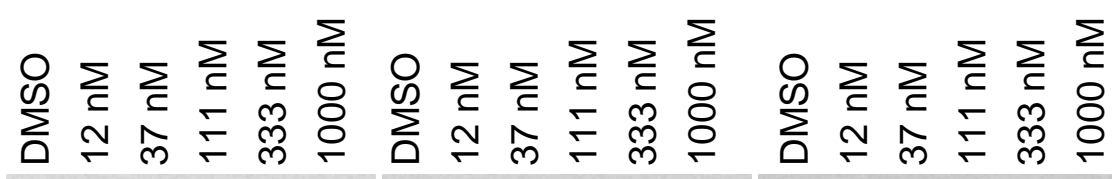

Sl-109

$-0-0-$

$m-m-m$

$-\infty-\infty$

12

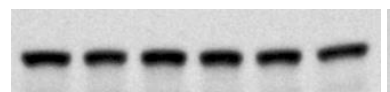

$-----$

$-\infty-\infty$

14

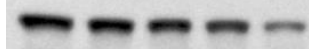

$-\cdots-\cdots$

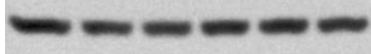

SD-36

15

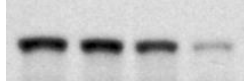

$--$

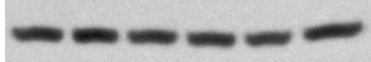

16

$m-\infty$
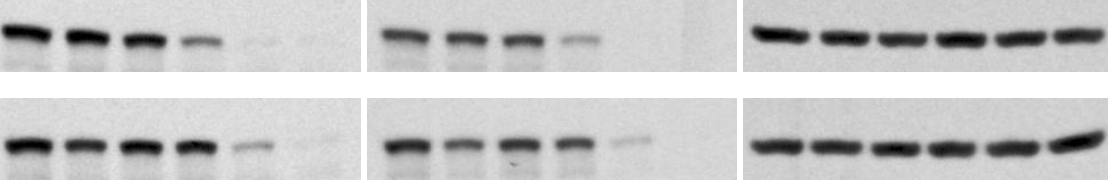

B

STAT3 p-STAT3 ${ }^{\text {Y705 }}$

\section{$\beta$-actin}

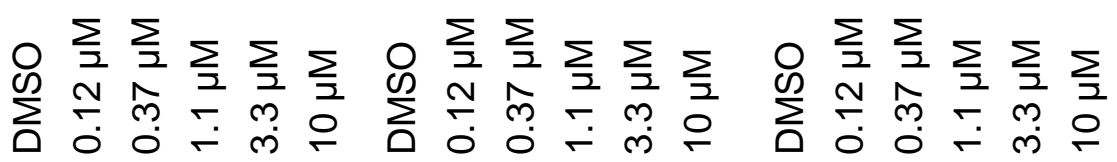

12

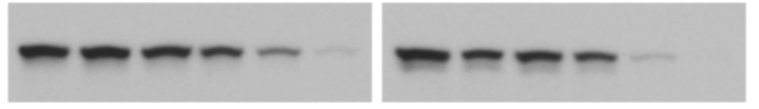

$--\infty$

Figure S3. STAT3 degraders with various linker lengths. (A) and (B) Western blotting analysis of total STAT3 and p-STAT3 ${ }^{\mathrm{Y} 705}$ proteins in Molm-16 cells treated with indicated compounds for $4 \mathrm{~h}$. 
A STAT3 p-STAT3 ${ }^{\text {Y705 }}$

$\beta$-actin

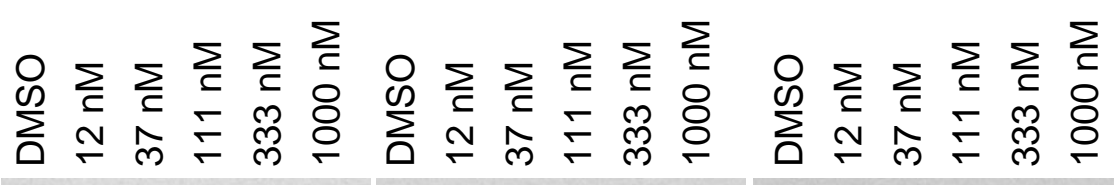
SD-36

$m-\infty$

$m-\infty$
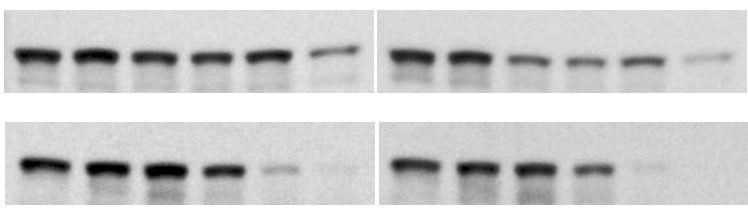

$\omega 00000000$

19

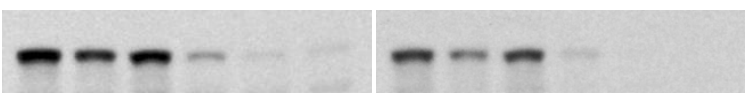

20

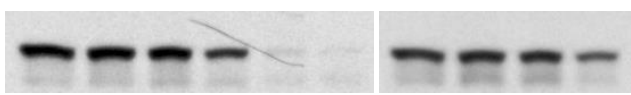

21

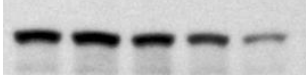

$-\infty-\infty$

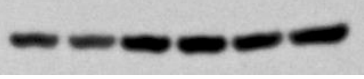

22

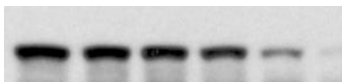

$m-m-\infty$
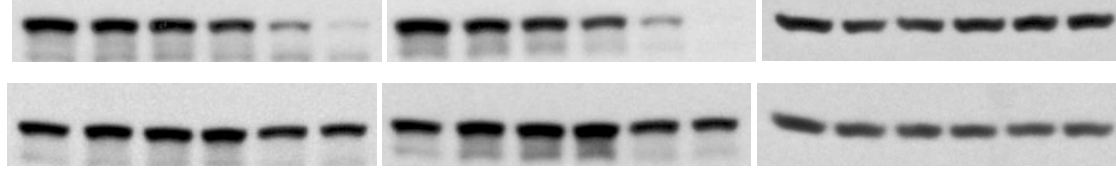

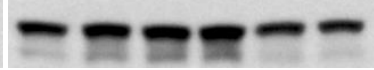

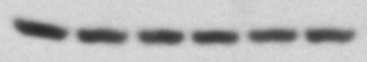

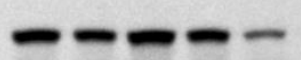

$-m-$
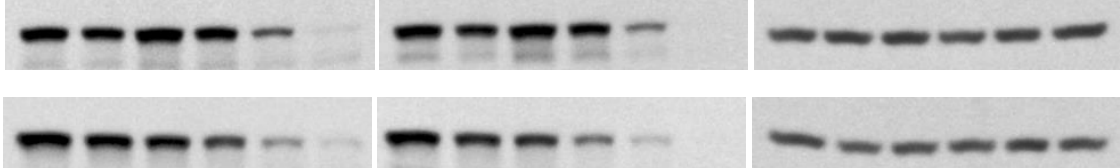

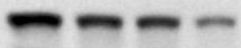

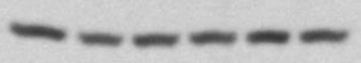

26

$m-\infty$

$m-\infty$

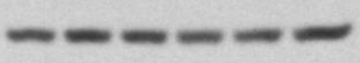

B

\section{STAT3 p-STAT3 ${ }^{\text {Y705 }} \quad \beta_{\text {-actin }}$}

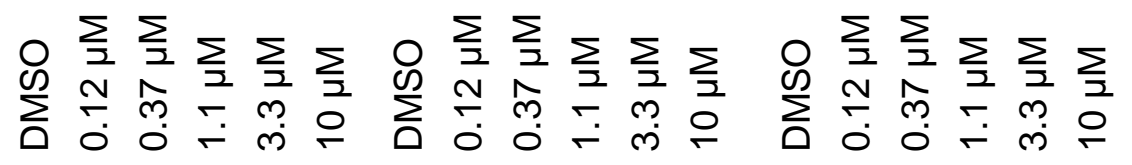

Figure S4. Western blotting analysis of total STAT3 and p-STAT3 ${ }^{\mathrm{Y} 705}$ proteins in Molm-16 cells treated with indicated compounds for $4 \mathrm{~h}$. 
A

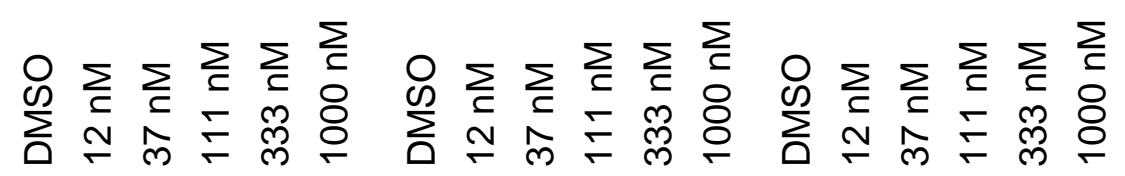

\section{SD-36}

30
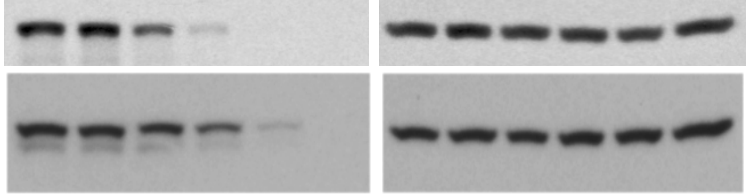

B STAT3 p-STAT3 ${ }^{\text {Y705 }} \quad \beta$-actin

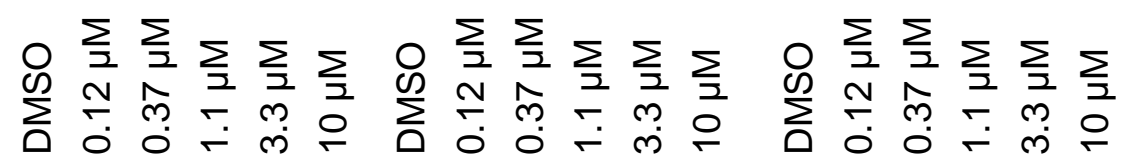
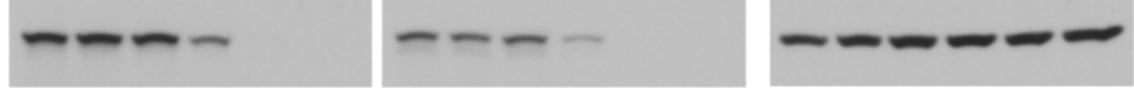

Figure S6. Western blotting analysis of total STAT3 and p-STAT3 ${ }^{\mathrm{Y} 705}$ proteins in Molm-16 cells treated with indicated compounds for $4 \mathrm{~h}$. 


\section{STAT3 p-STAT3 ${ }^{\text {Y705 }} \beta$-actin}

32

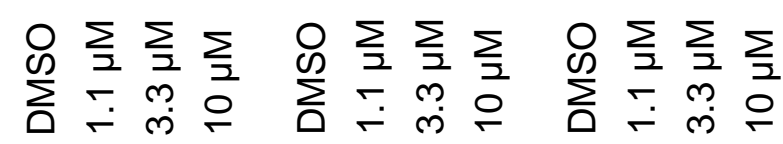

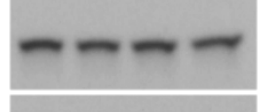

33

34

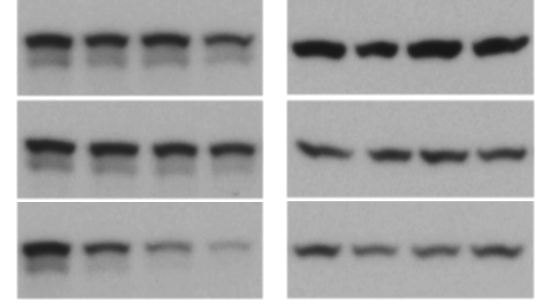

Figure S7. Western blotting analysis of total STAT3 and p-STAT3 ${ }^{\mathrm{Y} 705}$ proteins in Molm-16 cells treated with indicated compounds for $4 \mathrm{~h}$. 


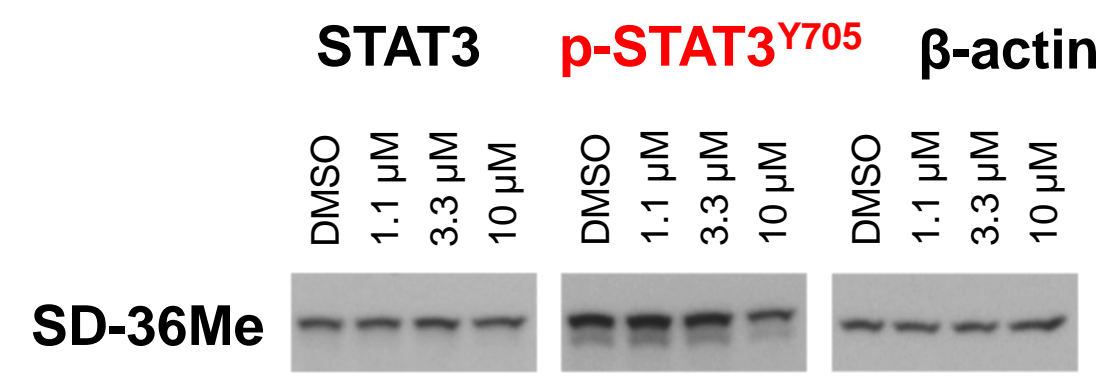

Figure S8. Western blotting analysis of total STAT3 and p-STAT3 ${ }^{\mathrm{Y} 705}$ proteins in Molm-16 cells treated with SD-36Me for $4 \mathrm{~h}$. 


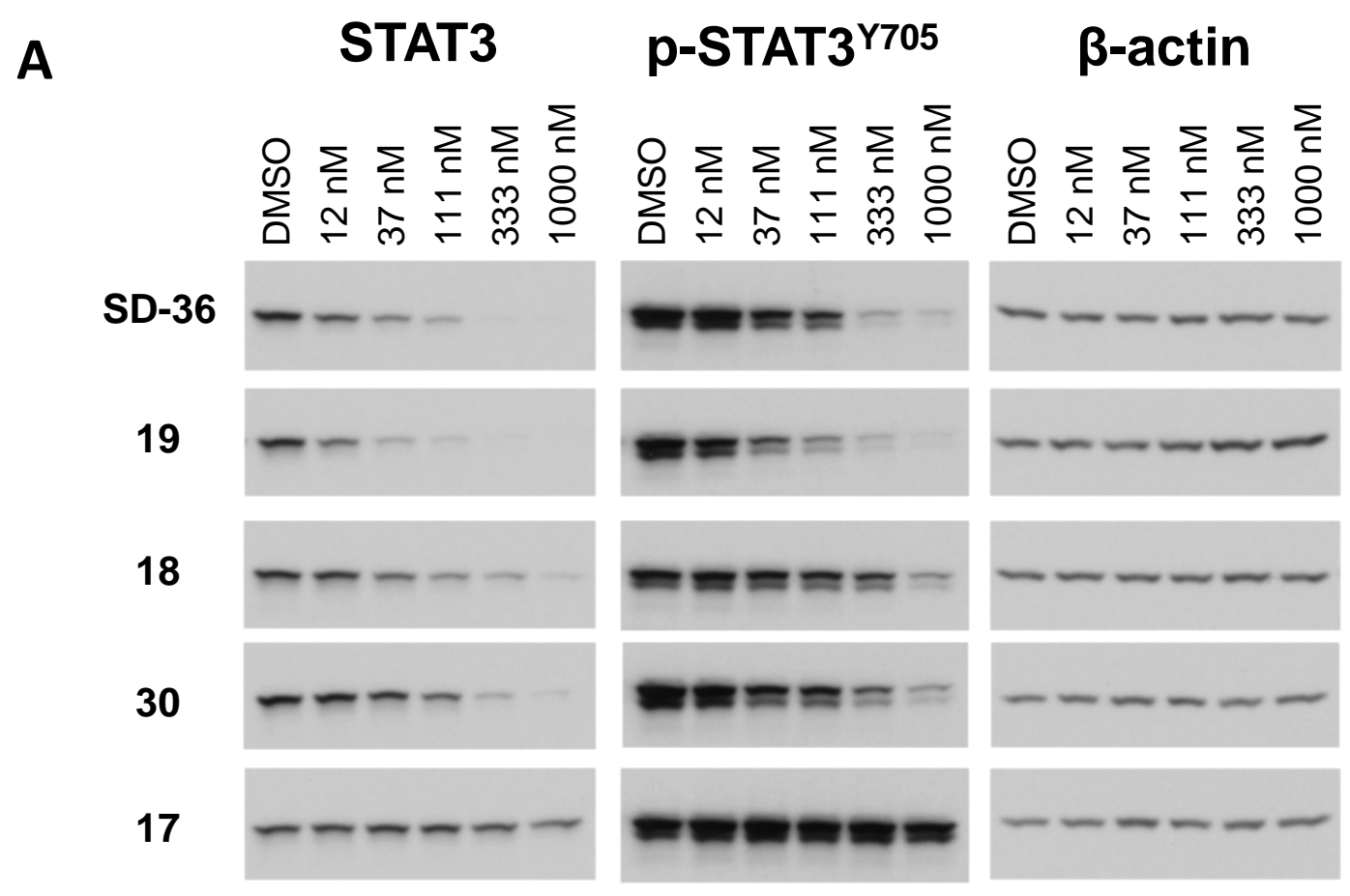

B

STAT3

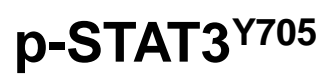

\section{$\beta$-actin}

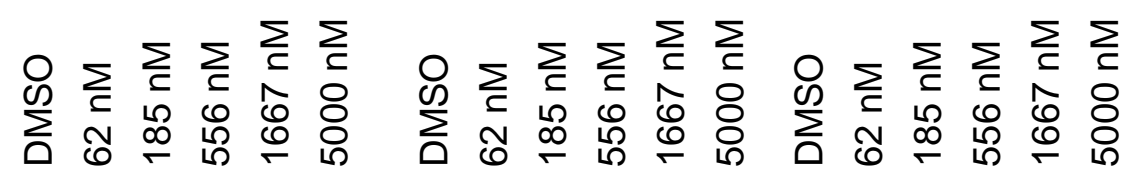

31
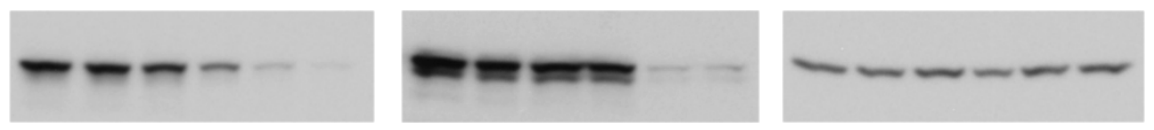

27
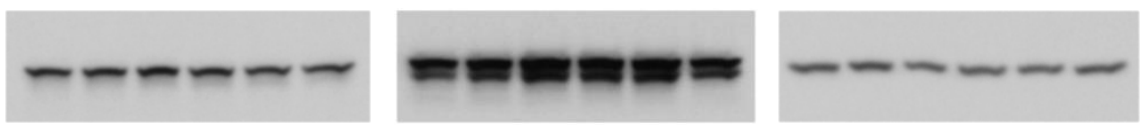

34
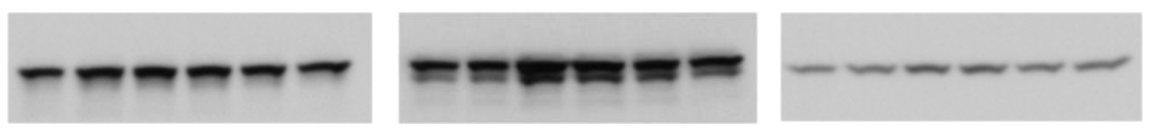

Figure S9. Western blotting analysis of total STAT3 and p-STAT3 ${ }^{\mathrm{Y} 705}$ proteins in SU-DHL1cell line treated with treated with representative STAT3 degraders for $16 \mathrm{~h}$. 
${ }^{1} \mathrm{H}$ NMR for compound 5 .

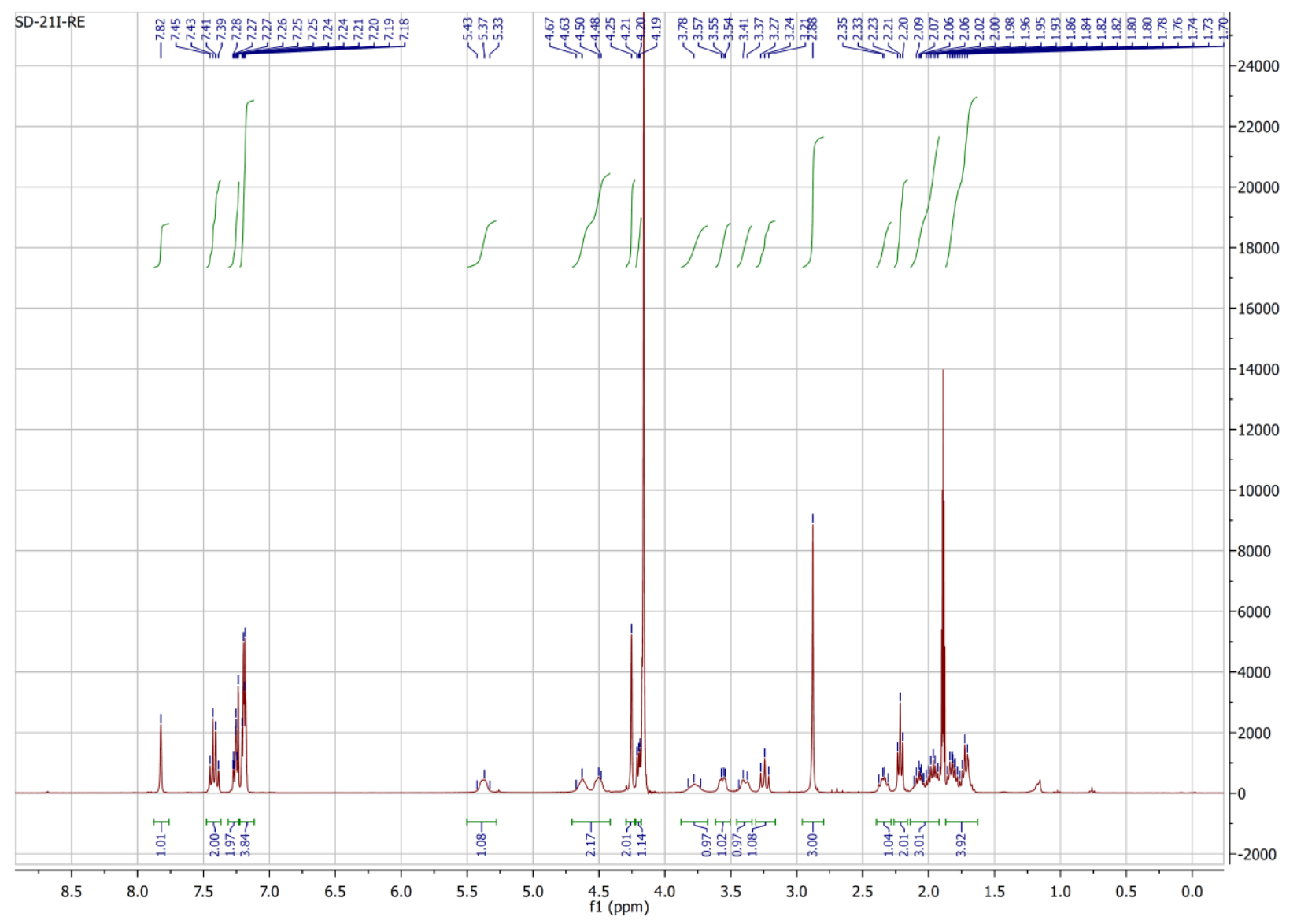


UPLC-MS analysis for compound $\mathbf{5}$.

\begin{tabular}{|llll|}
\hline \multicolumn{3}{c|}{ S A M P L E } & I N F O R M A T I O N \\
\hline \hline Sample Name: & ZH-SD-21I & Acquired By: & System \\
Sample Type: & Unknown & Date Acquired: & $3 / 25 / 2019$ 7:30:26 PM EDT \\
Vial: & $1: C, 6$ & Acq. Method Set: & 10 to100\% Bin 10 min_Delay5min \\
Injection \#: & 1 & Date Processed: & $3 / 28 / 2019$ 6:30:31 PM EDT \\
Injection Volume: & 3.00 ul & Processing Method: & Bruce \\
Run Time: & 10.0 Minutes & Channel Name: & 230.0nm@1 \\
Sample Set Name: 3 & Proc. Chnl. Descr.: & PDA Spectrum PDA 230.0 nm (PDf \\
\hline
\end{tabular}

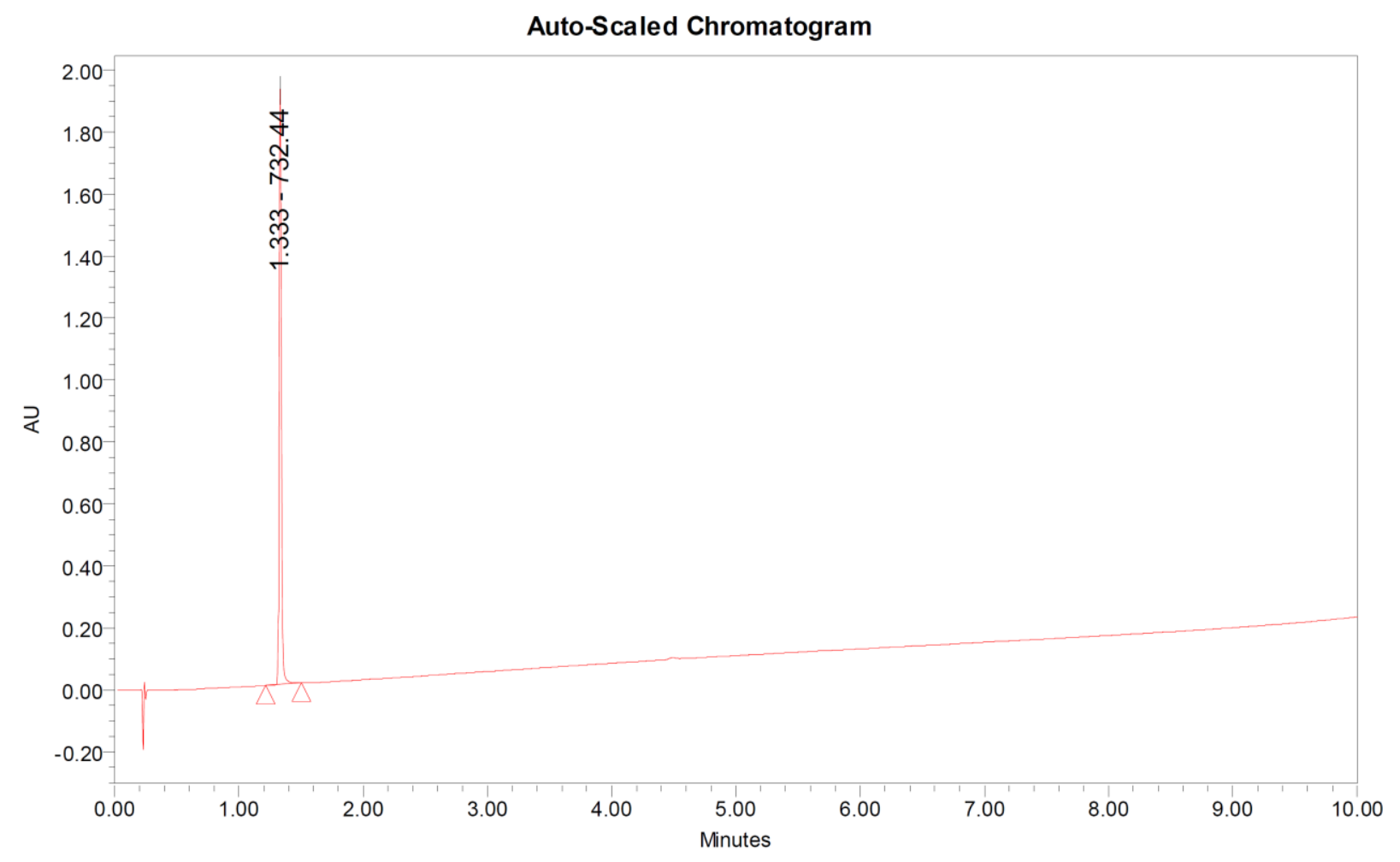

\begin{tabular}{|c|c|c|c|c|}
\multicolumn{9}{|c|}{ Peak Results } \\
\hline & RT & Area & Height & $\%$ Area \\
\hline 1 & 1.333 & 2436390 & 1921951 & 100.00 \\
\hline
\end{tabular}

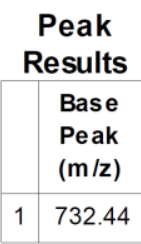


${ }^{1} \mathrm{H}$ NMR for compound 7.

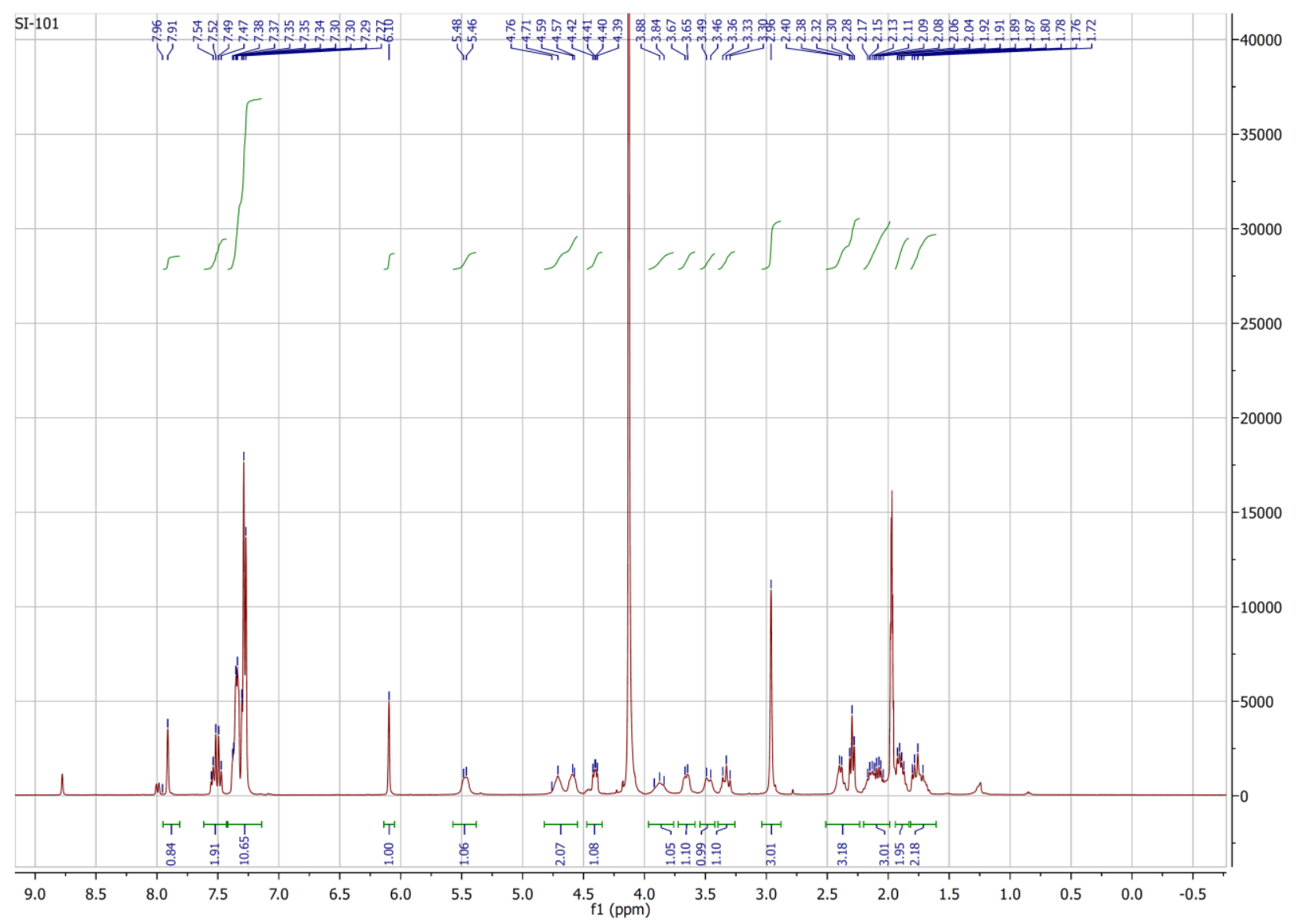


UPLC-MS analysis for compound 7.

\begin{tabular}{|llll|}
\hline & \multicolumn{2}{c|}{ S A M P L E } & I N F O R M A T I O N \\
\hline \hline Sample Name: & zh-si101 & Acquired By: & System \\
Sample Type: & Unknown & Date Acquired: & $12 / 21 / 2018$ 2:30:11 PM EST \\
Vial: & $1: A, 7$ & Acq. Method Set: & 10 to100\% Bin 10 min_Delay5min \\
Injection \#: & 1 & Date Processed: & $12 / 21 / 2018$ 2:47:46 PM EST \\
Injection Volume: & 8.00 ul & Processing Method: & Bruce \\
Run Time: & 10.0 Minutes & Channel Name: & 230.0nm \\
Sample Set Name: & aa & Proc. Chnl. Descr.: & PDA Spectrum PDA 230.0 nm (PDf \\
\hline
\end{tabular}

Auto-Scaled Chromatogram

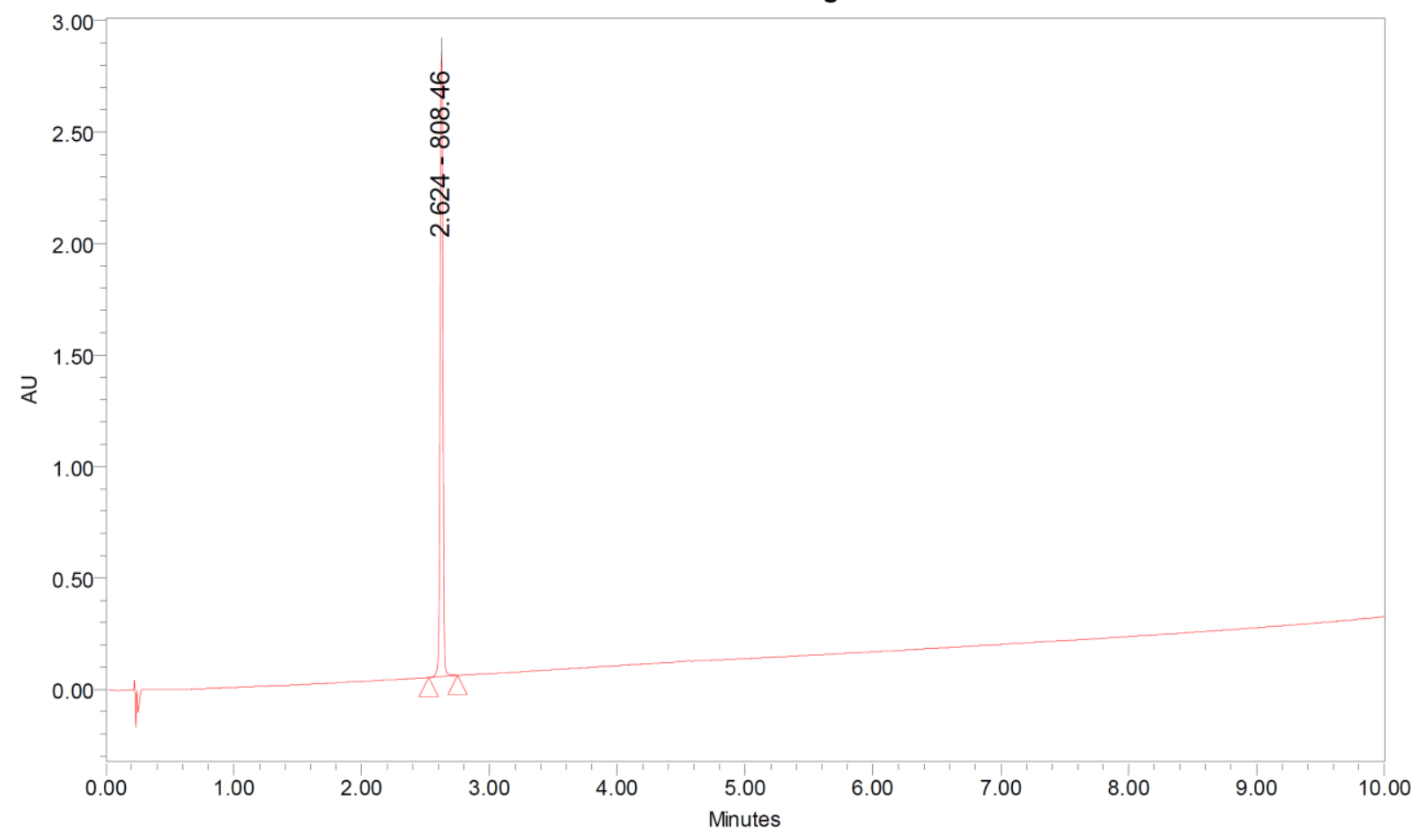

\begin{tabular}{|l|c|c|c|c|}
\hline \multicolumn{5}{|c|}{ Peak Results } \\
\begin{tabular}{|c|c|c|c|c|}
\hline & RT & Area & Height & $\%$ Area \\
\hline 1 & 2.624 & 4182693 & 2803694 & 100.00 \\
\hline
\end{tabular}
\end{tabular}

Peak

Results

Base

Peak

$(\mathrm{m} / \mathrm{z})$

1808.46 
${ }^{1} \mathrm{H}$ NMR for SI-109 (8).

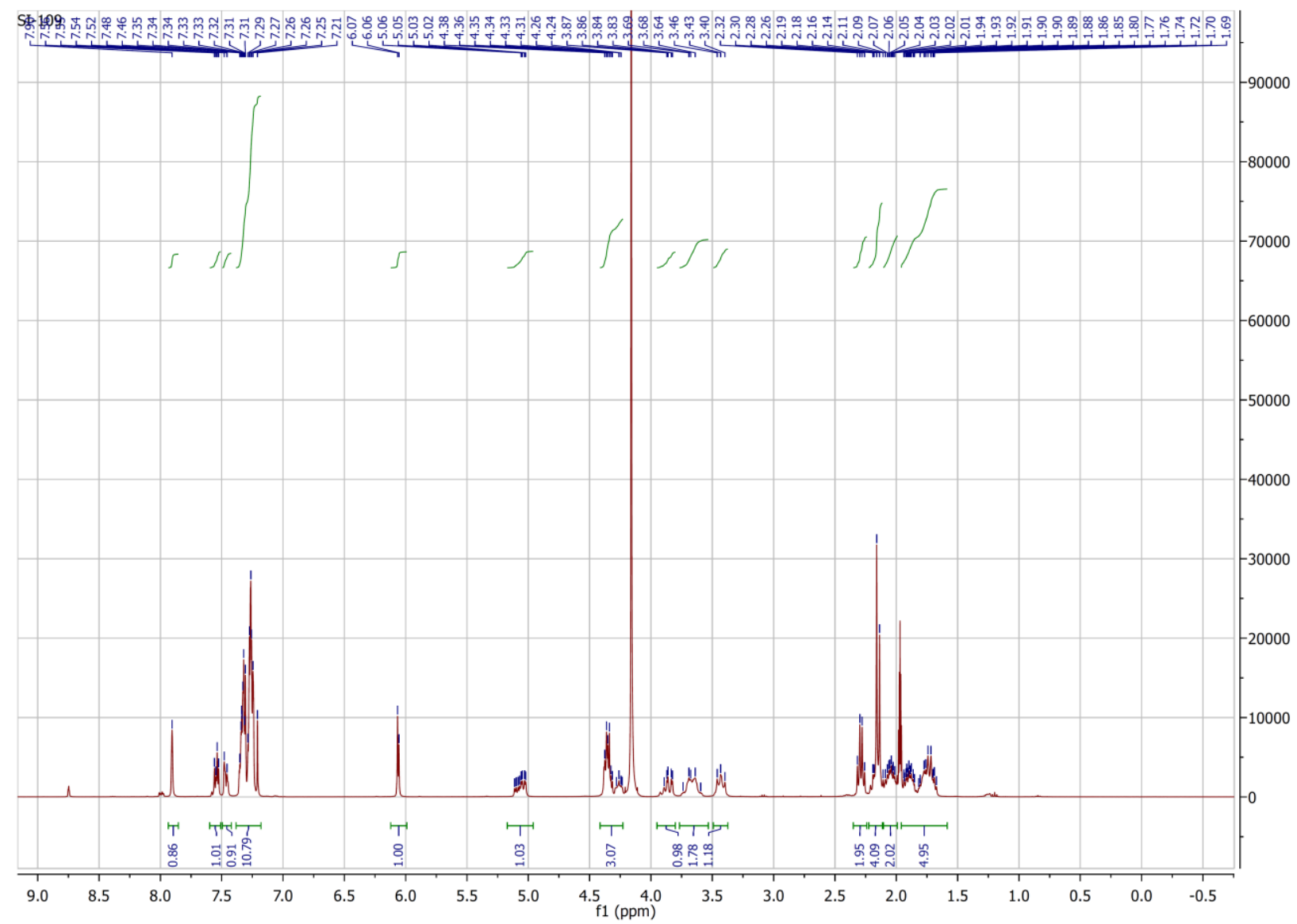


UPLC-MS analysis for SI-109 (8).

\begin{tabular}{|llll|}
\hline & \multicolumn{2}{c|}{ S A M P L E } & I N F O R M A T I O N \\
\hline \hline Sample Name: & zh-si-109 & Acquired By: & System \\
Sample Type: & Unknown & Date Acquired: & $12 / 21 / 2018$ 1:19:31 PM EST \\
Vial: & $1: A, 5$ & Acq. Method Set: & 10 to100\% Bin 10 min_Delay5min \\
Injection \#: & 1 & Date Processed: & $12 / 21 / 2018$ 2:15:32 PM EST \\
Injection Volume: & $8.00 \mathrm{ul}$ & Processing Method: & Bruce \\
Run Time: & 10.0 Minutes & Channel Name: & 230.0nm \\
Sample Set Name: & aa & Proc. Chnl. Descr.: & PDA Spectrum PDA 230.0 nm (PDA \\
\hline
\end{tabular}

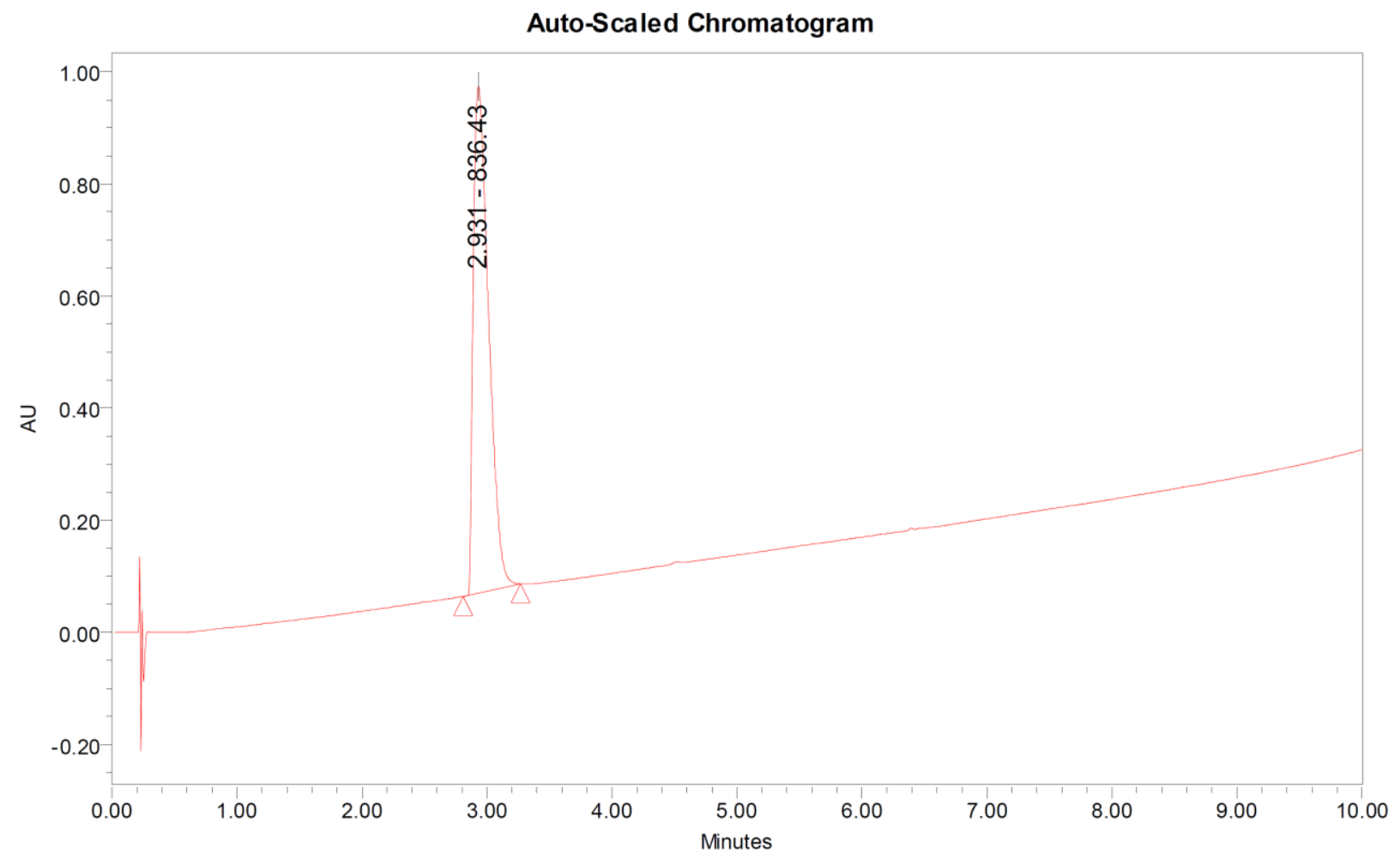

\begin{tabular}{|c|c|c|c|c|}
\hline \multicolumn{5}{|c|}{ Peak Results } \\
\hline & RT & Area & Height & $\%$ Area \\
\hline 1 & 2.931 & 7675966 & 904157 & 100.00 \\
\hline
\end{tabular}


${ }^{1} \mathrm{H}$ NMR for compound $\mathbf{1 2}$.

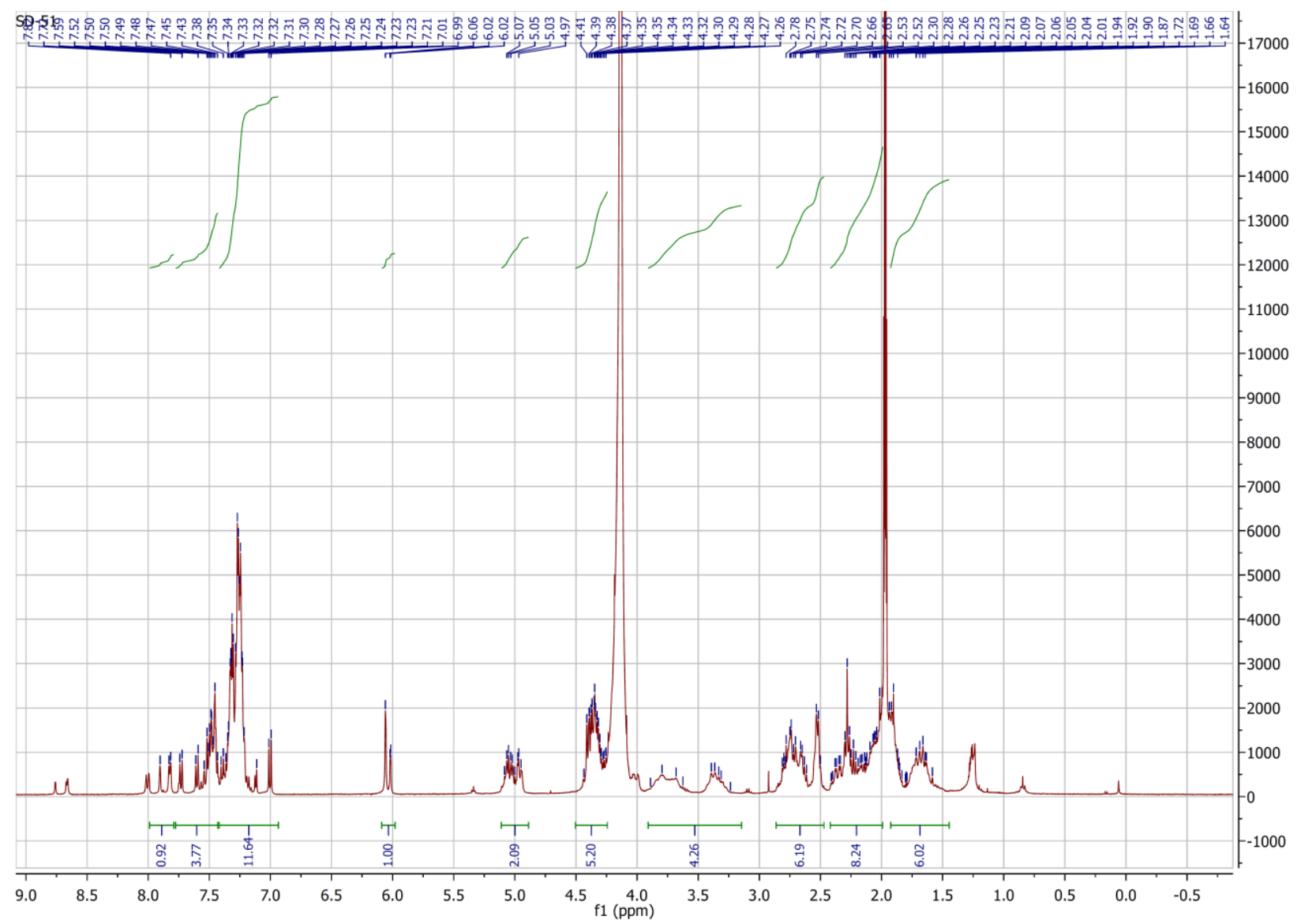


UPLC-MS analysis for compound $\mathbf{1 2 .}$

\begin{tabular}{|c|c|c|c|}
\hline \multicolumn{2}{|r|}{ SAMPLE } & \multicolumn{2}{|c|}{ I NFORMATION } \\
\hline $\begin{array}{l}\text { Sample Name: } \\
\text { Sample Type: }\end{array}$ & $\begin{array}{l}\text { ZH-SD-51 } \\
\text { Unknown }\end{array}$ & $\begin{array}{l}\text { Acquired By: } \\
\text { Date Acquired: }\end{array}$ & $\begin{array}{l}\text { System } \\
\text { 9/6/2018 11:34:14 AM EDT }\end{array}$ \\
\hline Vial: & $1: E, 5$ & Acq. Method Set: & 10to $100 \%$ Bin 10 \\
\hline $\begin{array}{l}\text { Injection \#: } \\
\text { Injection Volume: }\end{array}$ & $\begin{array}{l}1 \\
3.00 \mathrm{ul}\end{array}$ & $\begin{array}{l}\text { Date Processed: } \\
\text { Processing Method: }\end{array}$ & $\begin{array}{l}\text { rei6/20el|lay15manta PM EDT } \\
\text { Bruce }\end{array}$ \\
\hline Run Time: & 10.0 Minutes & Channel Name: & $230.0 \mathrm{~nm}$ \\
\hline Sample Set Name: & Shilin & Proc. Chnl. Descr.: & PDA Spectrum $(210-500) \mathrm{nm}$ \\
\hline
\end{tabular}

\section{Auto-Scaled Chromatogram}

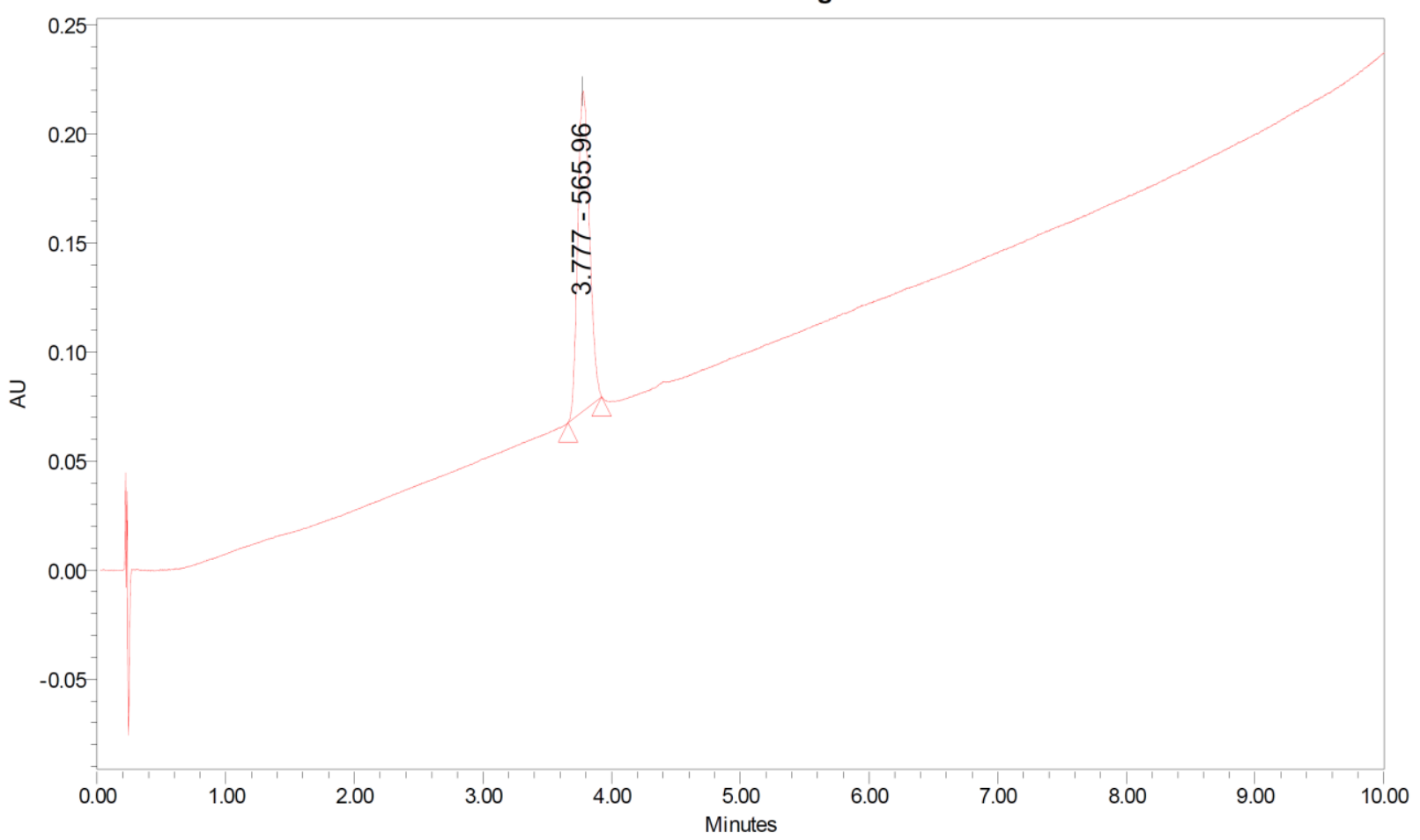

Peak Results
\begin{tabular}{|l|l|l|l|l|l|}
\hline & RT & Area & Height & $\%$ Area & $\begin{array}{l}\text { Base } \\
\text { Peak } \\
(\mathbf{m} / \mathbf{z})\end{array}$ \\
\hline 1 & 3.777 & 935129 & 146756 & 100.00 & 565.96 \\
\hline
\end{tabular}


${ }^{1} \mathrm{H}$ NMR for SD-36 (14).

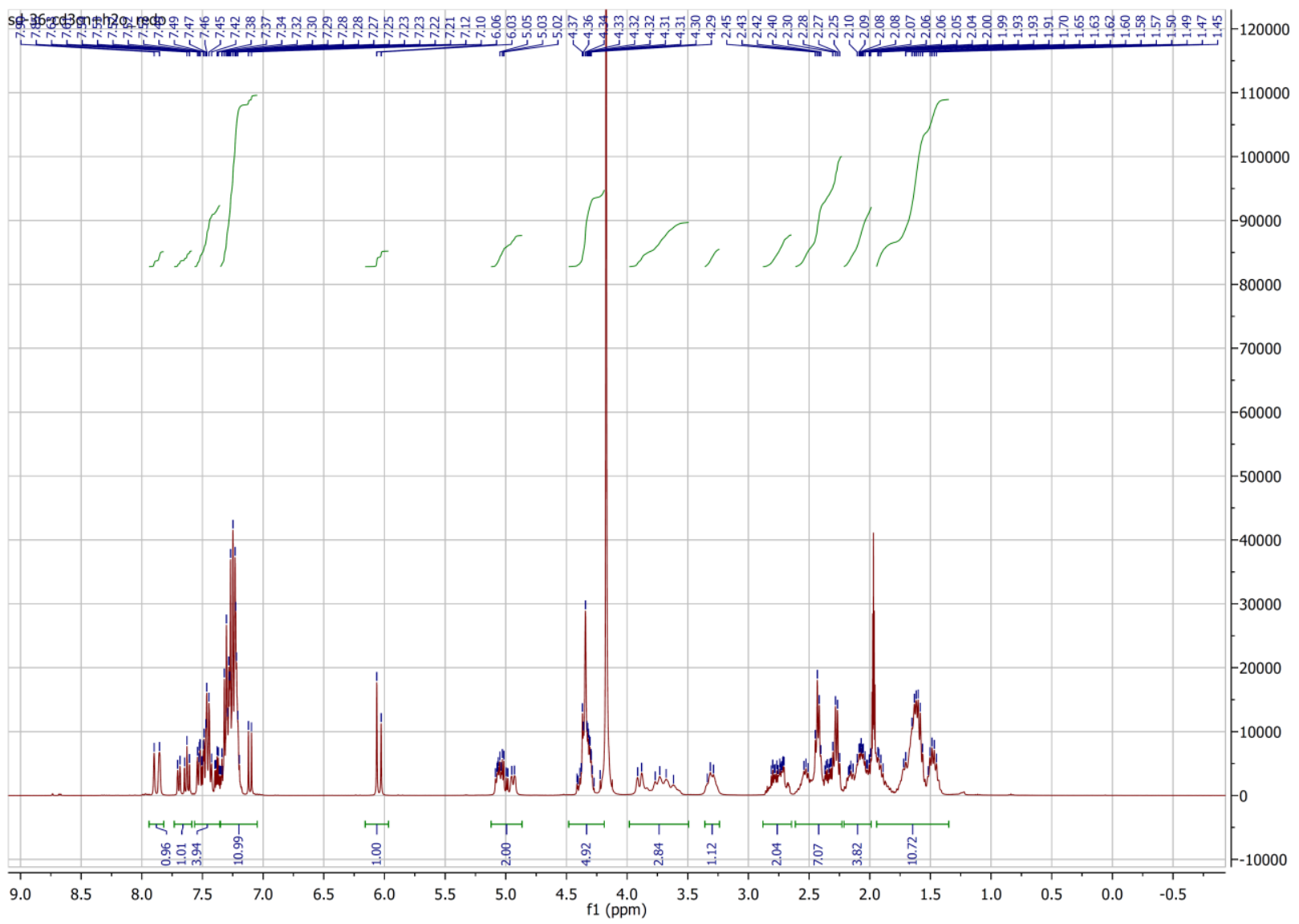


UPLC-MS analysis for SD-36 (14).

\begin{tabular}{|c|c|c|c|}
\hline \multicolumn{2}{|r|}{ SAMPLE } & \multicolumn{2}{|c|}{ INFORMATION } \\
\hline $\begin{array}{l}\text { Sample Name: } \\
\text { Sample Type: }\end{array}$ & $\begin{array}{l}\text { ZH-SD-36 } \\
\text { Unknown }\end{array}$ & $\begin{array}{l}\text { Acquired By: } \\
\text { Date Acquired: }\end{array}$ & $\begin{array}{l}\text { System } \\
\text { 7/16/2018 6:39:40 PM EDT }\end{array}$ \\
\hline Vial: & $1: F, 7$ & Acq. Method Set: & 10to $100 \%$ Bin 10 \\
\hline $\begin{array}{l}\text { Injection \#: } \\
\text { Injection Volume: }\end{array}$ & $\begin{array}{l}1 \\
3.00 \mathrm{ul}\end{array}$ & $\begin{array}{l}\text { Date Processed: } \\
\text { Processing Method }\end{array}$ & 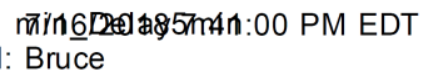 \\
\hline Run Time: & 10.0 Minutes & Channel Name: & 230.0nm@1 \\
\hline Sample Set Name & Shilin & Proc. Chnl. Descr.: & PDA Spectrum $(210-500) \mathrm{nm}$ \\
\hline
\end{tabular}

Auto-Scaled Chromatogram

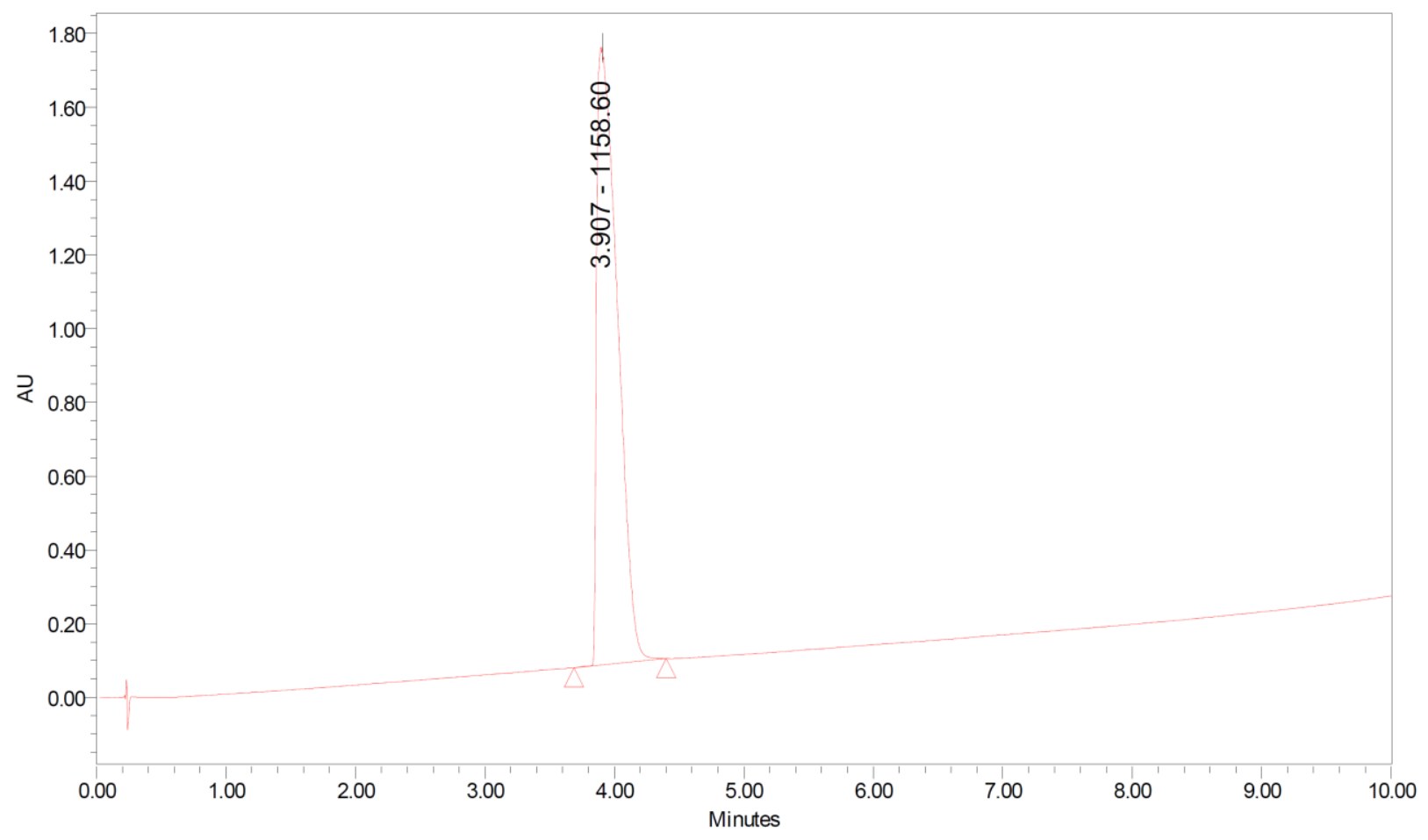

Peak Results

\begin{tabular}{|c|c|c|c|c|c|}
\hline & RT & Area & Height & \% Area & $\begin{array}{c}\text { Base } \\
\text { Peak } \\
\text { (m/z) }\end{array}$ \\
\hline 1 & 3.907 & 18527168 & 1674564 & 100.00 & 1158.60 \\
\hline
\end{tabular}




\section{${ }^{1} \mathrm{H}$ NMR for compound 19.}

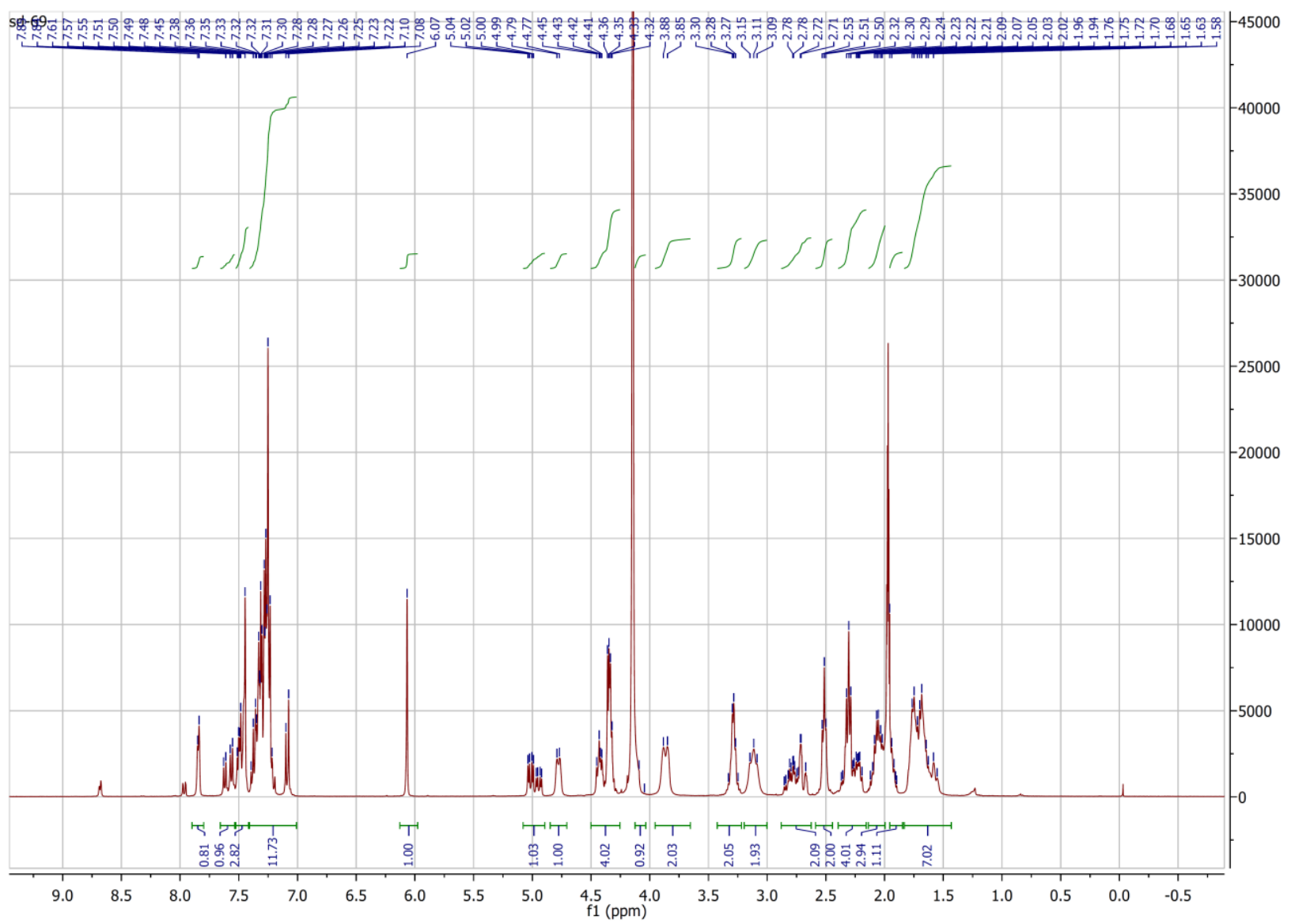


UPLC-MS analysis for compound 19.

\begin{tabular}{|c|c|c|c|}
\hline \multicolumn{4}{|c|}{ INFORMATION } \\
\hline Sample Name: & SD-69 & Acquired By. & System \\
\hline Sample Type: & Utknown & Date Acquired: & 811620182:42-48PMEDT \\
\hline Vial: & $1: B, 5$ & Acc Method Set & 10 to100\%Bin 10 min_Delay5min \\
\hline Irijection\#. & 1 & Date Processed: & 8/16/20185:48:00PM̄̄ET \\
\hline lijection Volume: & $3.00 \mathrm{u}$ & Processing Method: & Bruce \\
\hline RunTime: & 10.0 Mnutes & Cramel Name: & $230.0 \mathrm{~mm}$ \\
\hline Sample Set Name: & SHUN & Proc. Ont. Descr:: & PDA SpectrumPDA $230.0 \mathrm{~m}$ (PDA Spectrum \\
\hline
\end{tabular}

AutoScaled Chromatogram

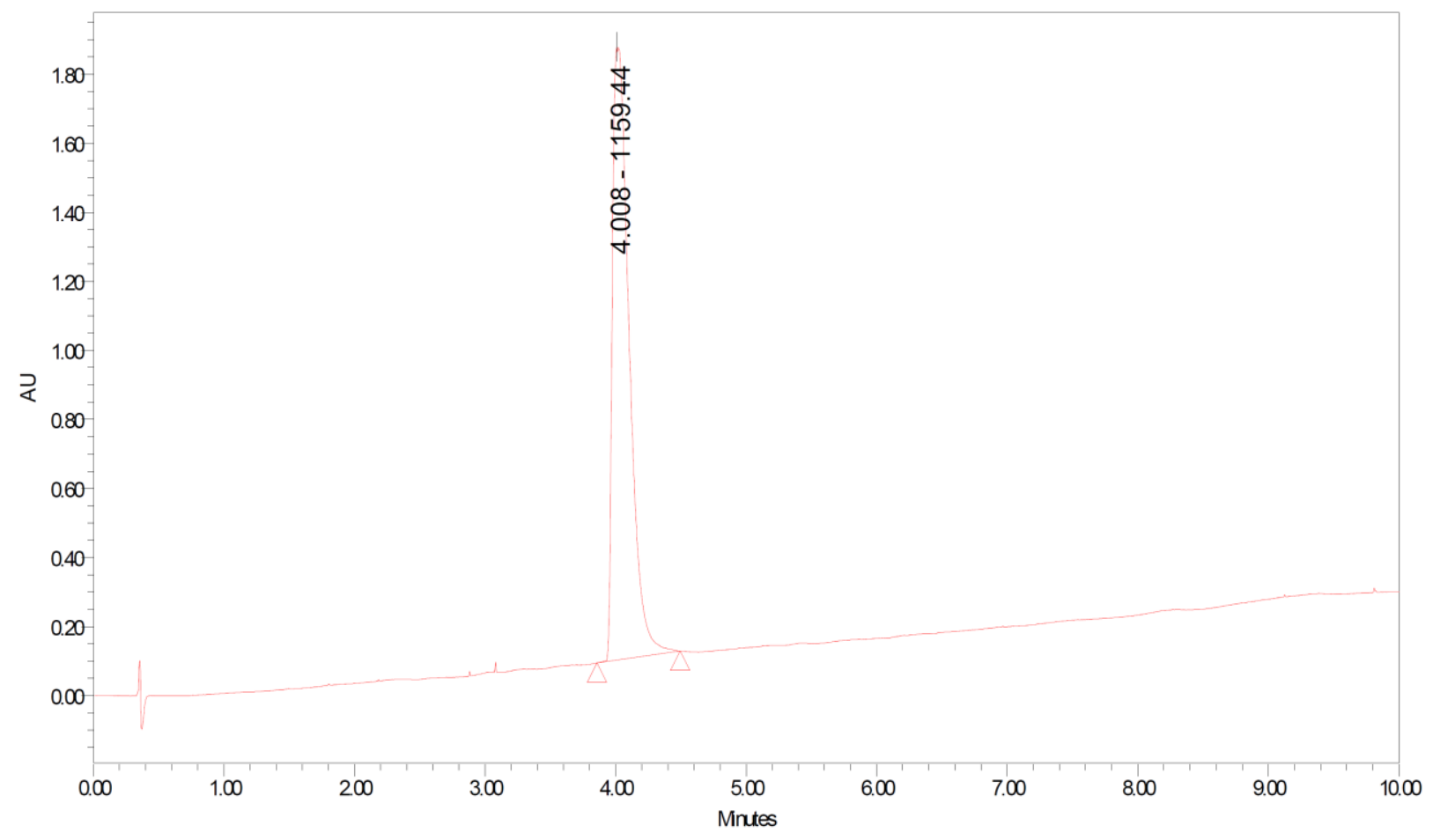

\section{PeakResults}

\begin{tabular}{|c|c|c|c|c|c|}
\hline & Rा & Area & Height & \%Area & $\begin{array}{c}\text { Bas } \\
\text { Peak } \\
\text { (m/z) }\end{array}$ \\
\hline 1 & 4.008 & 15901123 & 1776487 & 100.00 & 1159.44 \\
\hline
\end{tabular}


${ }^{1} \mathrm{H}$ NMR for compound 22.

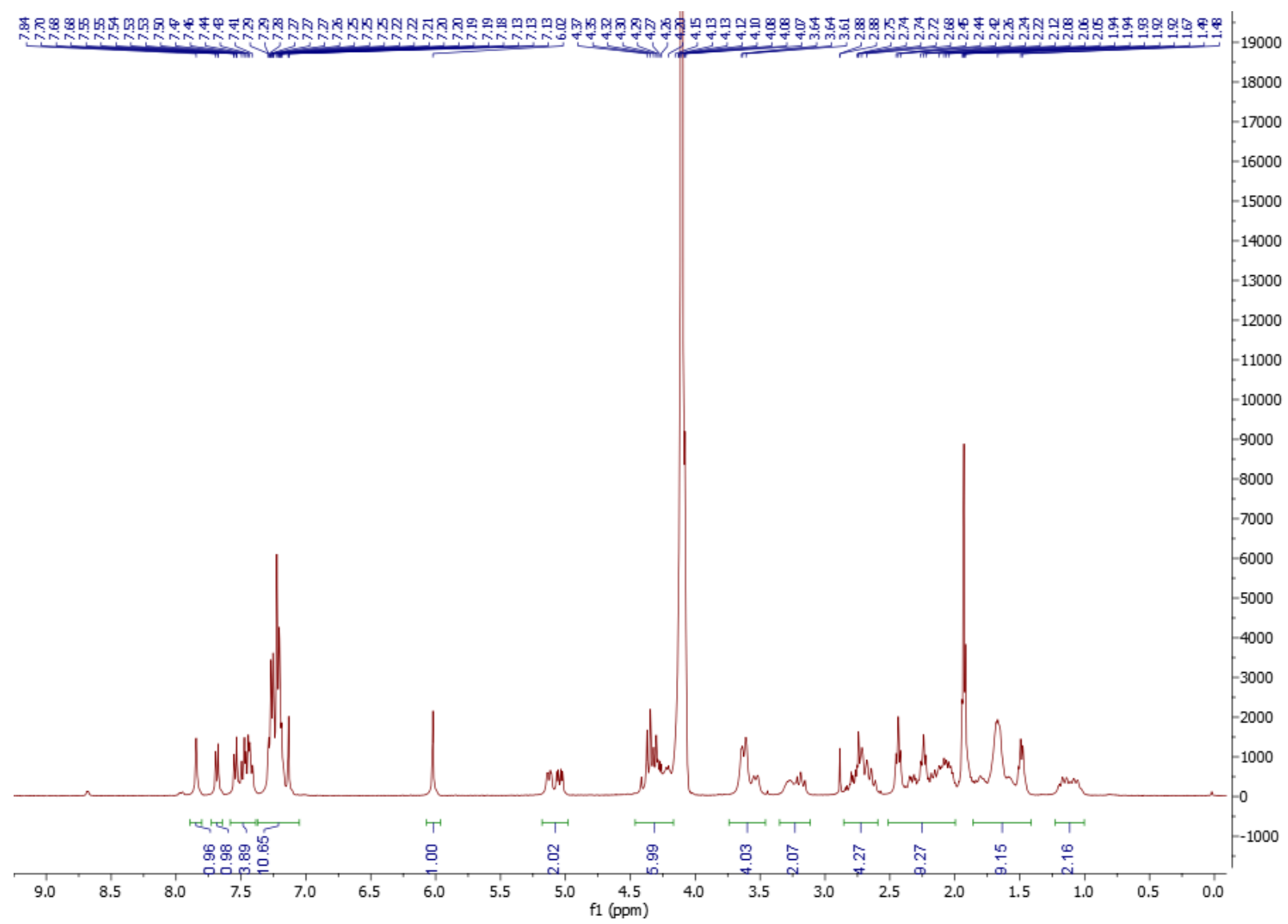


UPLC-MS analysis for compound 22.

\begin{tabular}{|c|c|c|c|}
\hline \multicolumn{2}{|r|}{ SAMPLE } & \multicolumn{2}{|c|}{ INFORMATION } \\
\hline $\begin{array}{l}\text { Sample Name: } \\
\text { Sample Type: }\end{array}$ & $\begin{array}{l}\text { XRQ-SD-356-2 } \\
\text { Unknown }\end{array}$ & $\begin{array}{l}\text { Acquired By: } \\
\text { Date Acquired: }\end{array}$ & $\begin{array}{l}\text { System } \\
\text { 10/16/2018 9:46:12 PM EDT }\end{array}$ \\
\hline Vial: & $1: \mathrm{A}, 1$ & Acq. Method Set: & 10 to $100 \%$ Bin 10 \\
\hline $\begin{array}{l}\text { Injection \#: } \\
\text { Injection Volume: }\end{array}$ & $\begin{array}{l}1 \\
3.00 \mathrm{ul}\end{array}$ & $\begin{array}{l}\text { Date Processed: } \\
\text { Processing Method }\end{array}$ & 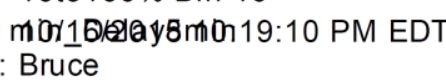 \\
\hline Run Time: & 10.0 Minutes & Channel Name: & 254.0nm@1 \\
\hline Sample Set Name: & Shilin & Proc. Chnl. Descr.: & PDA Spectrum $(210-500) \mathrm{nm}$ \\
\hline
\end{tabular}

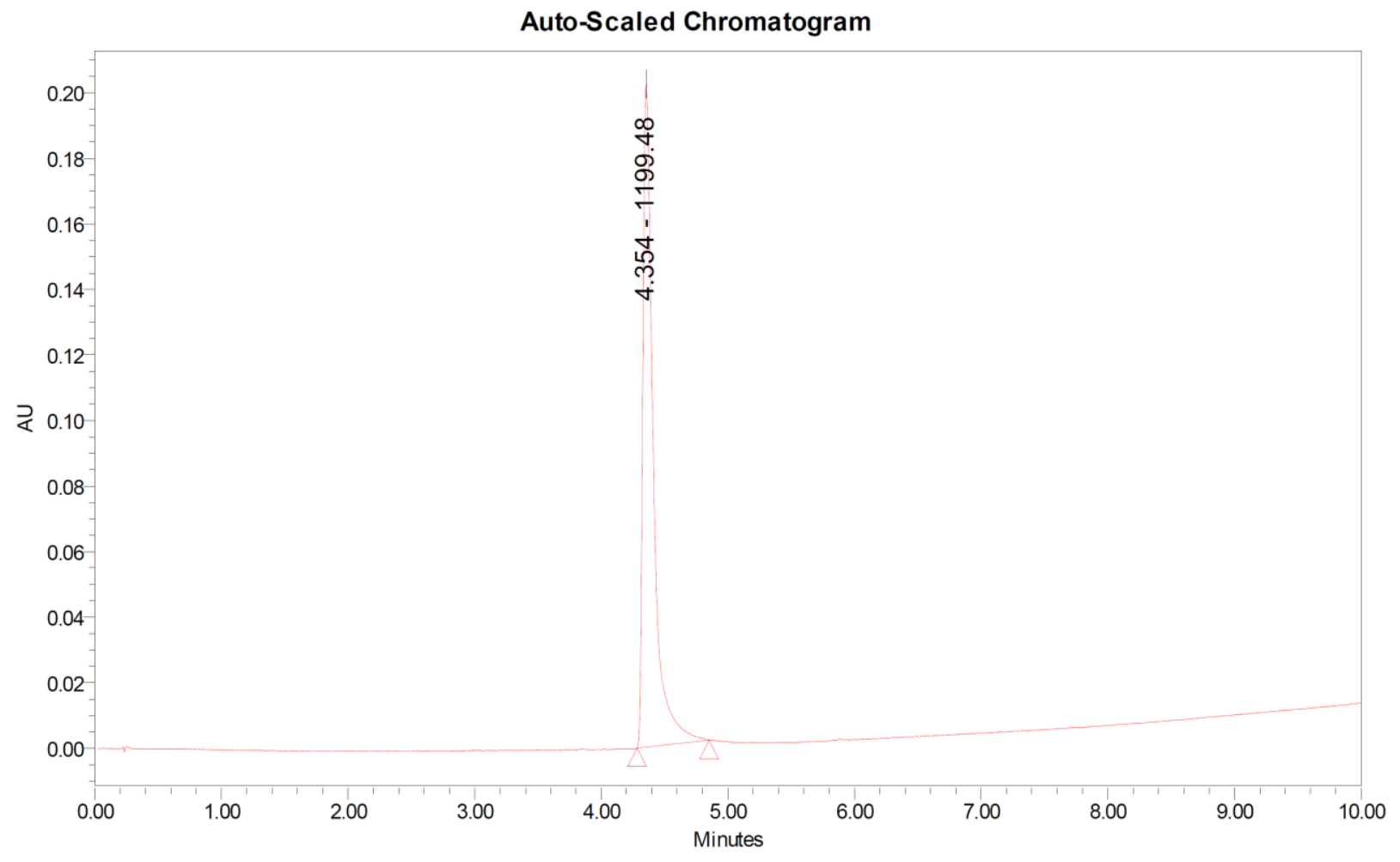

\begin{tabular}{|l|c|c|c|c|c|}
\hline \multicolumn{1}{|c|}{ Peak Results } \\
\hline & RT & Area & Height & $\%$ Area & $\begin{array}{c}\text { Base } \\
\text { Peak } \\
(\mathbf{m} / \mathbf{z})\end{array}$ \\
\hline 1 & 4.354 & 1169135 & 202098 & 100.00 & 1199.48 \\
\hline
\end{tabular}


${ }^{1} \mathrm{H}$ NMR for compound 26.

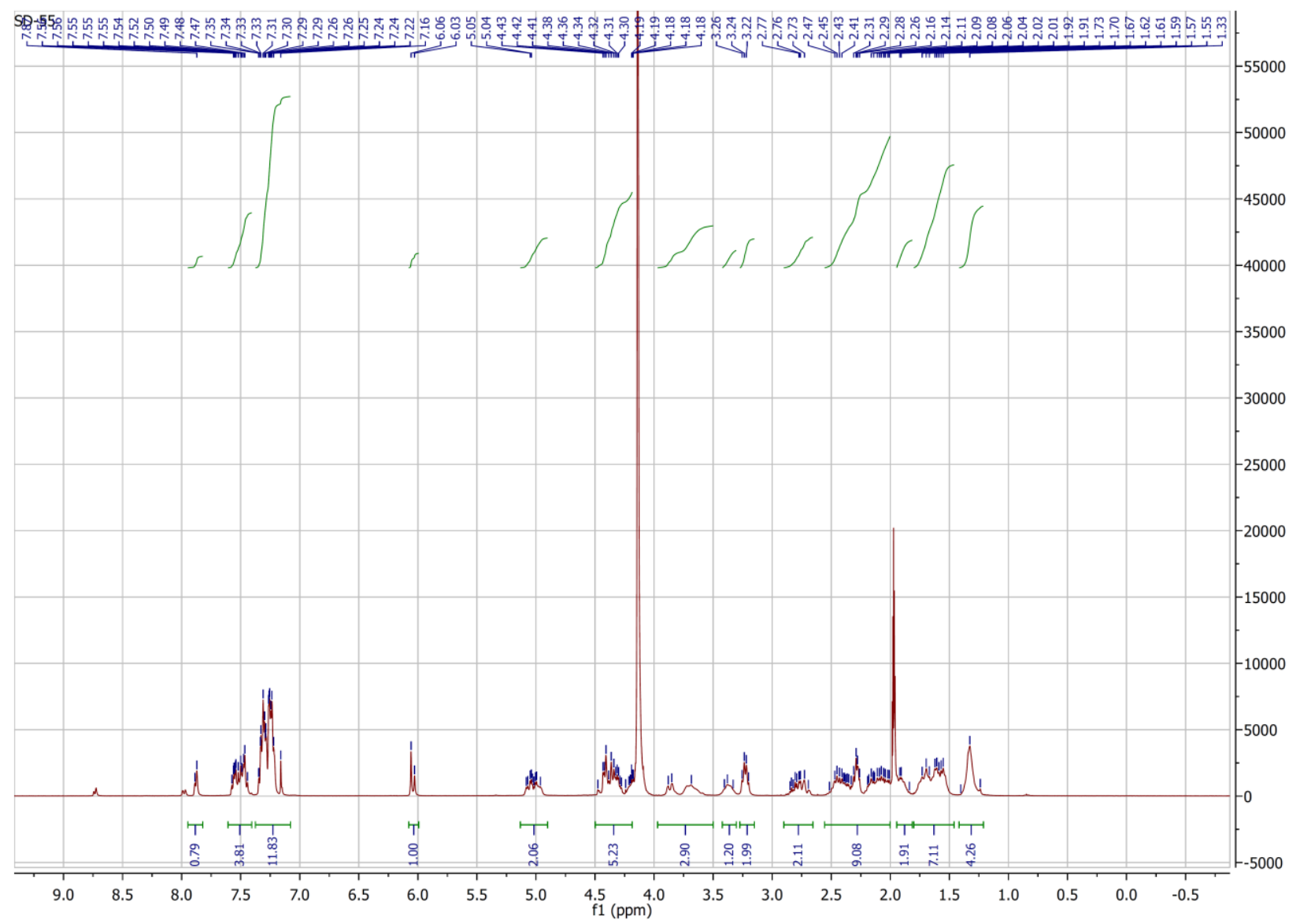


UPLC-MS analysis for compound 26.

\begin{tabular}{|c|c|c|c|}
\hline \multicolumn{2}{|r|}{ SAMPLE } & \multicolumn{2}{|c|}{ INFORMATION } \\
\hline $\begin{array}{l}\text { Sample Name: } \\
\text { Sample Type: }\end{array}$ & XRQ-SD-55 & $\begin{array}{l}\text { Acquired By: } \\
\text { Date Acquired: }\end{array}$ & $\begin{array}{l}\text { System } \\
\text { 9/6/2018 12:05.32 PM EDT }\end{array}$ \\
\hline $\begin{array}{l}\text { Sample Type: } \\
\text { Vial: }\end{array}$ & $\begin{array}{l}\text { Unknown } \\
1: E, 7\end{array}$ & $\begin{array}{l}\text { Date Acquired: } \\
\text { Acq. Method Set: }\end{array}$ & $\begin{array}{l}\text { 9/6/2018 12:05:32 PM EDT } \\
\text { 10to100\% Bin } 10\end{array}$ \\
\hline $\begin{array}{l}\text { Vial: } \\
\text { Injection \#: }\end{array}$ & $\begin{array}{l}1: E, 7 \\
1\end{array}$ & $\begin{array}{l}\text { Acq. Method Set: } \\
\text { Date Processed: }\end{array}$ & 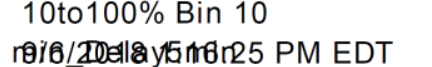 \\
\hline $\begin{array}{l}\text { Injection \#: } \\
\text { Injection Volume: }\end{array}$ & $3.00 \mathrm{ul}$ & Processing Method: & : Bruce \\
\hline Run Time: & 10.0 Minutes & Channel Name: & $230.0 \mathrm{~nm}$ \\
\hline Sample Set Name: & Shilin & Proc. Chnl. Descr.: & PDA Spectrum $(210-500) \mathrm{nm}$ \\
\hline
\end{tabular}

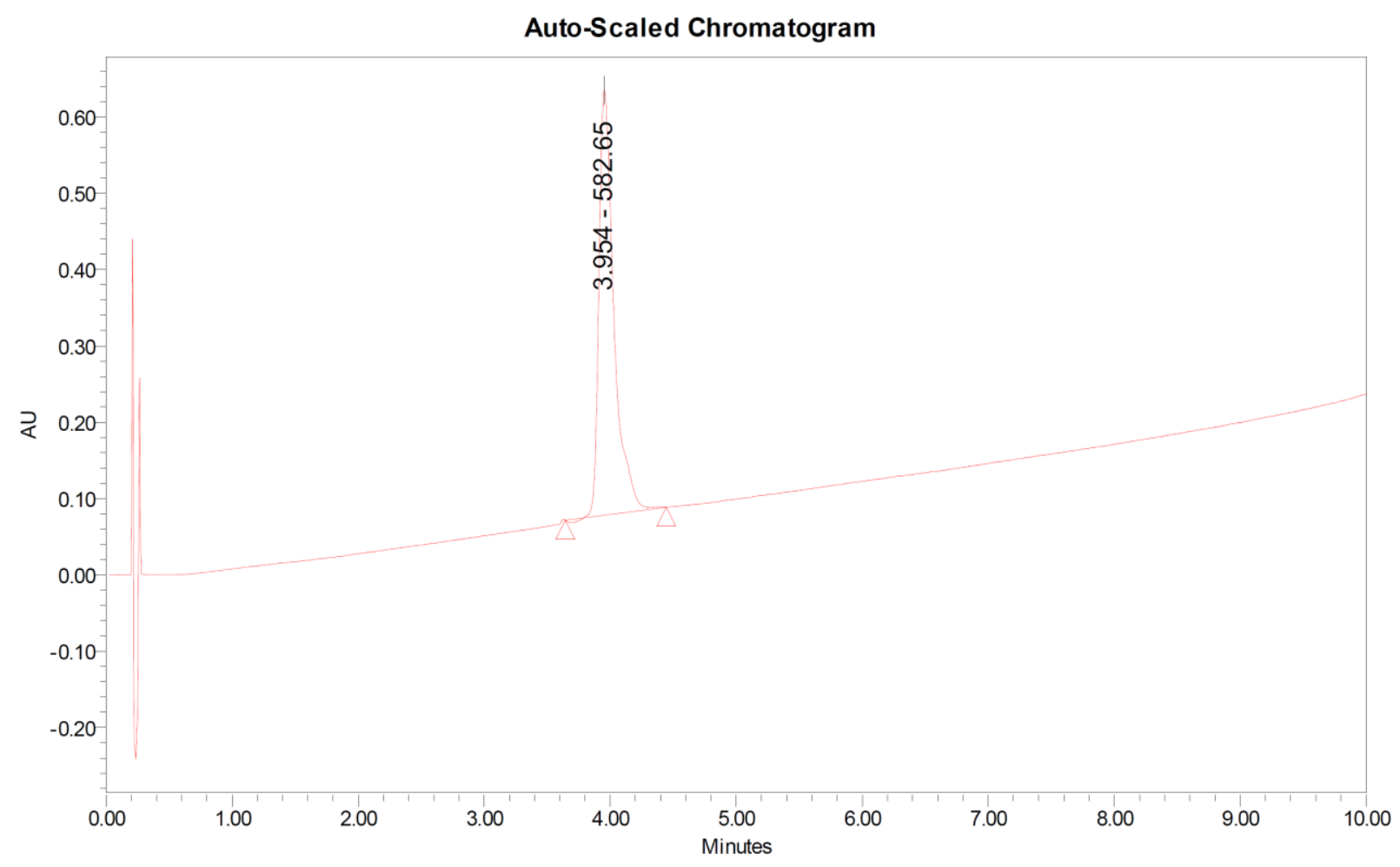

\begin{tabular}{|c|c|c|c|c|c|}
\hline \multicolumn{7}{|c|}{ Peak Results } \\
\hline & RT & Area & Height & $\%$ Area & $\begin{array}{l}\text { Base } \\
\text { Peak } \\
(\mathrm{m} / \mathbf{z})\end{array}$ \\
\hline 1 & 3.954 & 4619107 & 556371 & 100.00 & 582.65 \\
\hline
\end{tabular}


${ }^{1}$ H NMR for compound 27.

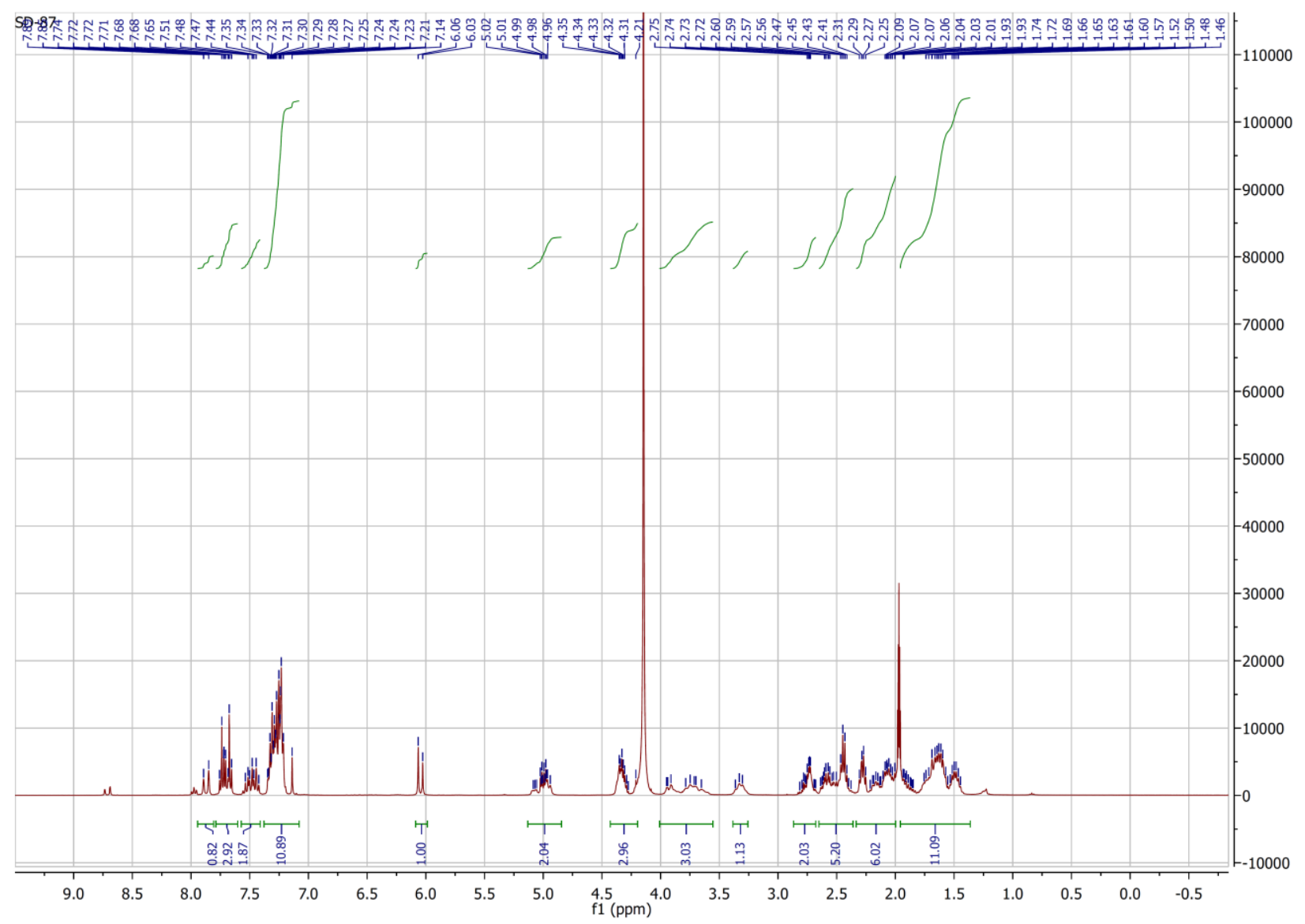


UPLC-MS analysis for compound 27.

\begin{tabular}{|c|c|c|c|}
\hline \multicolumn{4}{|c|}{ SAMPLE } \\
\hline Sample Name: & SD-87HPLC & Acquired By. & System \\
\hline Sample Type: & Utknown & Date Acquired: & 8/9/20183:01:42PMEDT \\
\hline Vial: & $1 \cdot \mathrm{A}, 8$ & Acq. Method Set & 10to100\%Bin 10min_Delay5min \\
\hline Irjection\#. & 1 & Date Processed: & 8/20184:26:41 PMEDT \\
\hline Irjection Volume: & $3.00 \mathrm{u}$ & Processing Method & Bruce \\
\hline RnTime: & 10.0 Mnutes & Chamel Name: & $230.0 \mathrm{~mm}$ \\
\hline Sample Set Name: & SHUN & Proc. Orn. Desar: & PDA SpectrumPDA $230.0 \mathrm{~mm}$ (PDA Spectrum \\
\hline
\end{tabular}

Auto-Scaled Chromatogram

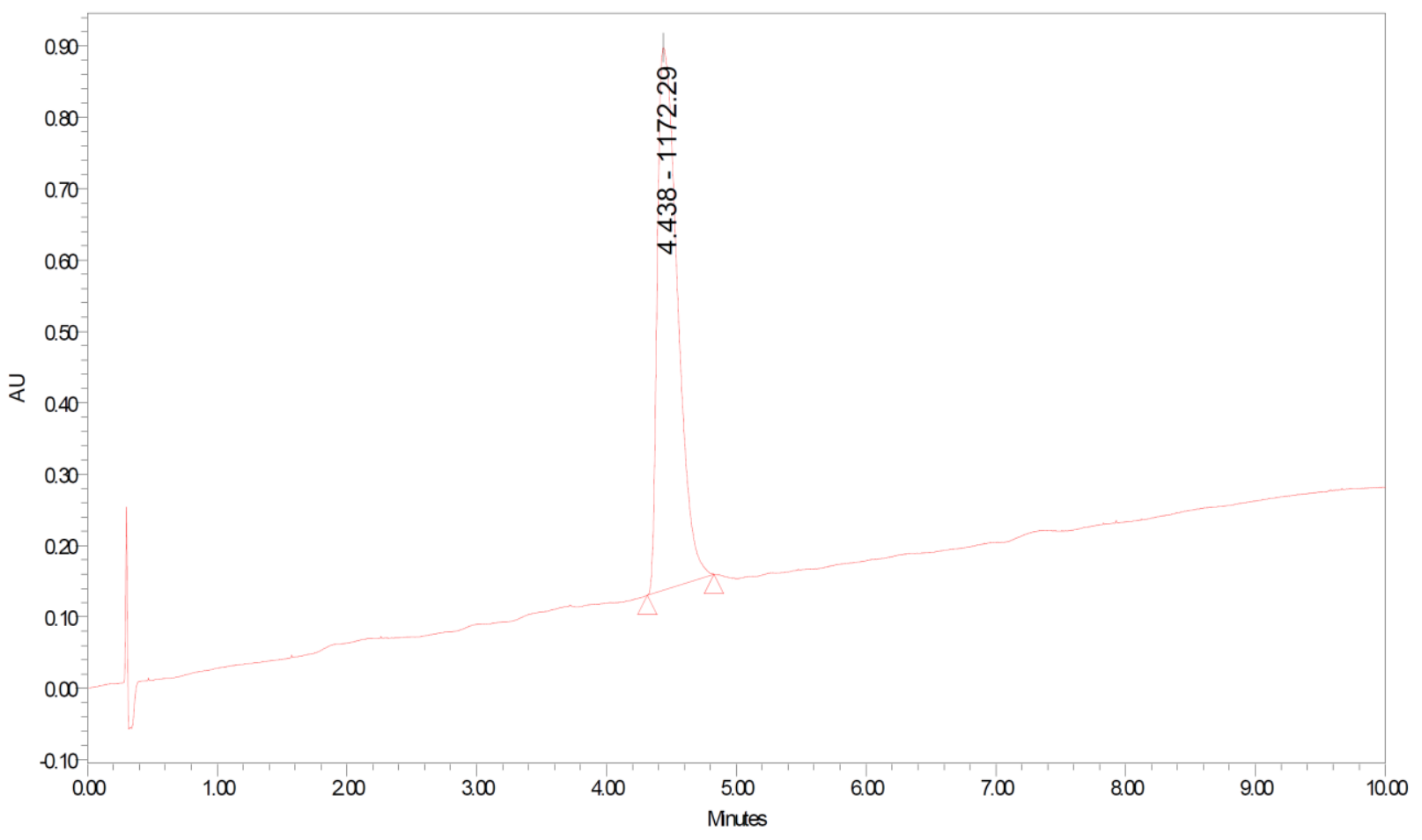

\begin{tabular}{|c|c|c|c|c|c|}
\hline & RT & Area & Height & $\%$ Area & $\begin{array}{c}\text { Bas } \\
\text { Peak } \\
\text { (m/z) }\end{array}$ \\
\hline 1 & 4.438 & 8206444 & 760771 & 100.00 & 117229 \\
\hline
\end{tabular}




\section{${ }^{1} \mathrm{H}$ NMR for compound $\mathbf{3 0}$.}

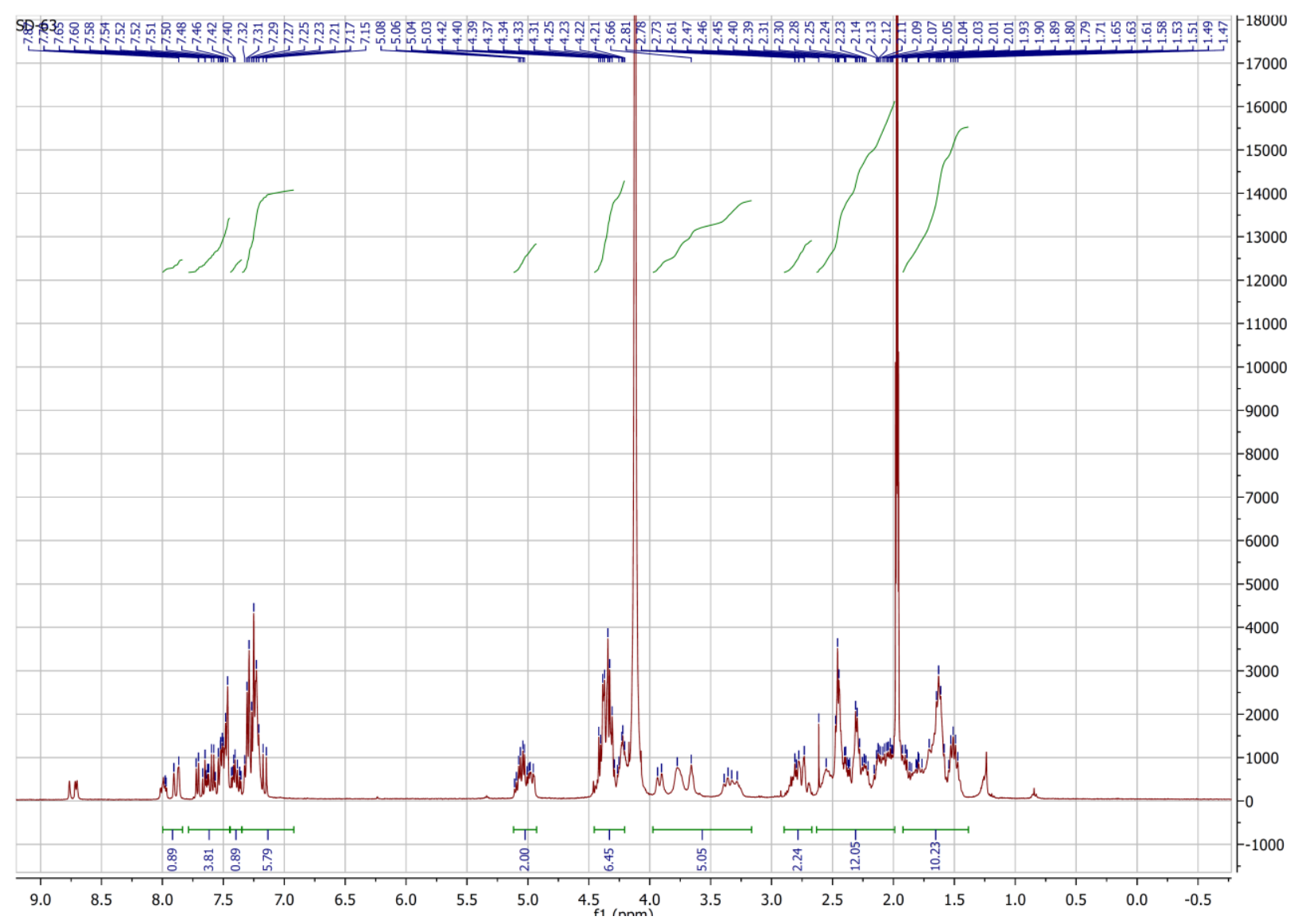


UPLC-MS analysis for compound $\mathbf{3 0 .}$

\begin{tabular}{|c|c|c|c|}
\hline \multicolumn{2}{|r|}{ SAMPLE } & \multicolumn{2}{|c|}{ INFORMATION } \\
\hline $\begin{array}{l}\text { Sample Name: } \\
\text { Sample Type: }\end{array}$ & $\begin{array}{l}\text { zh-sd-63 } \\
\text { Unknown }\end{array}$ & $\begin{array}{l}\text { Acquired By: } \\
\text { Date Acquired: }\end{array}$ & $\begin{array}{l}\text { System } \\
\text { 9/6/2018 4:09:22 PM EDT }\end{array}$ \\
\hline Vial: & $1: A, 3$ & Acq. Method Set: & 10to100\% Bin 10 \\
\hline $\begin{array}{l}\text { Injection \#: } \\
\text { Injection Volume: }\end{array}$ & $\begin{array}{l}1 \\
3.00 \mathrm{ul}\end{array}$ & $\begin{array}{l}\text { Date Processed: } \\
\text { Processing Method }\end{array}$ & 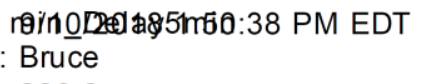 \\
\hline Run Time: & 10.0 Minutes & Channel Name: & $230.0 \mathrm{~nm}$ \\
\hline \multicolumn{2}{|c|}{ Sample Set Name:aa } & Proc. Chnl. Descr.: & PDA Spectrum $(210-500) \mathrm{nm}$ \\
\hline
\end{tabular}

Auto-Scaled Chromatogram

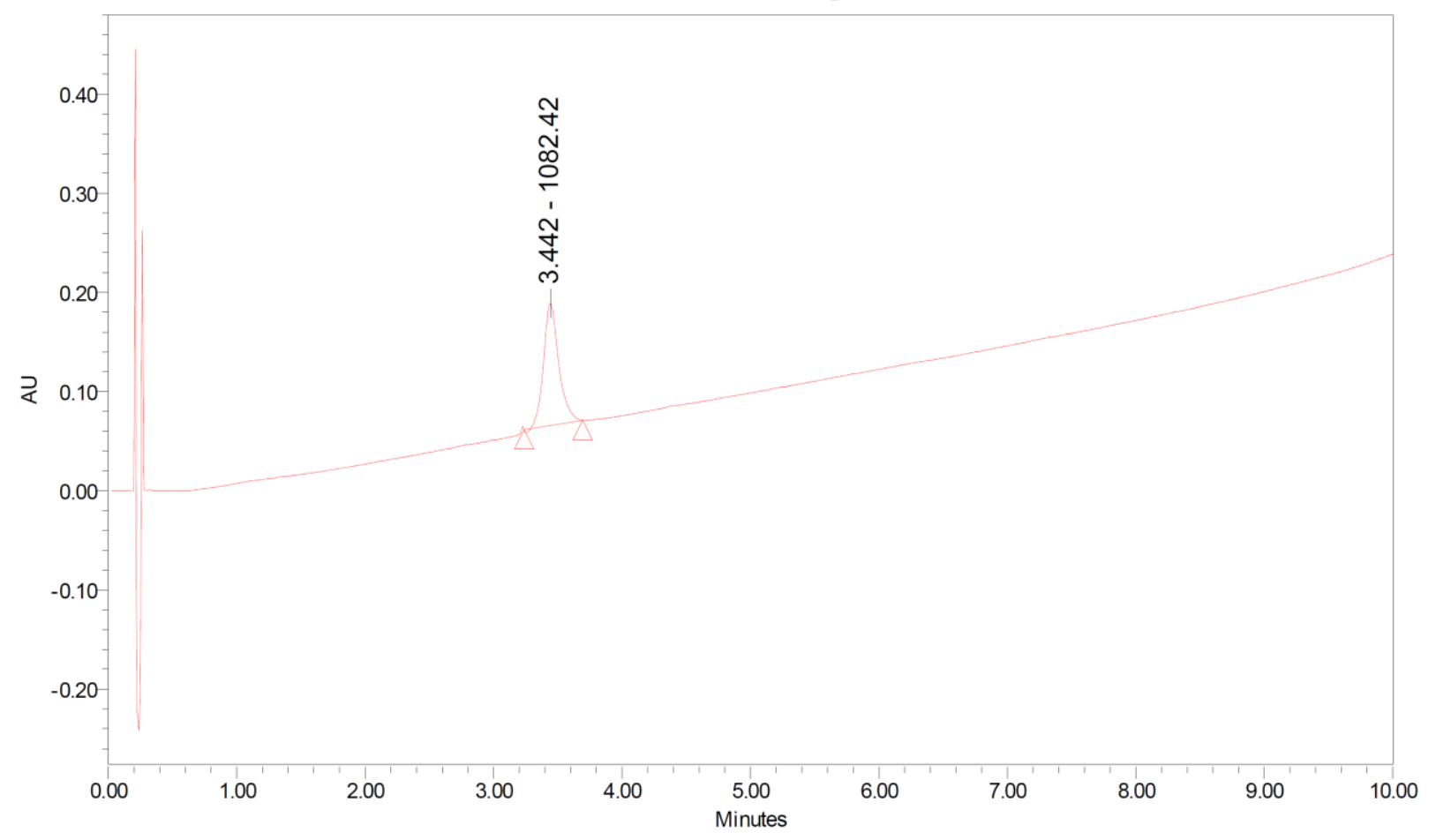

\begin{tabular}{|c|c|c|c|c|c|}
\hline \multicolumn{1}{|c|}{ Peak Results } \\
\hline & RT & Area & Height & $\%$ Area & $\begin{array}{c}\text { Base } \\
\text { Peak } \\
(\mathbf{m} / \mathbf{z})\end{array}$ \\
\hline 1 & 3.442 & 1023610 & 123259 & 100.00 & 1082.42 \\
\hline
\end{tabular}




\section{${ }^{1} \mathrm{H}$ NMR for compound $\mathbf{3 2}$.}

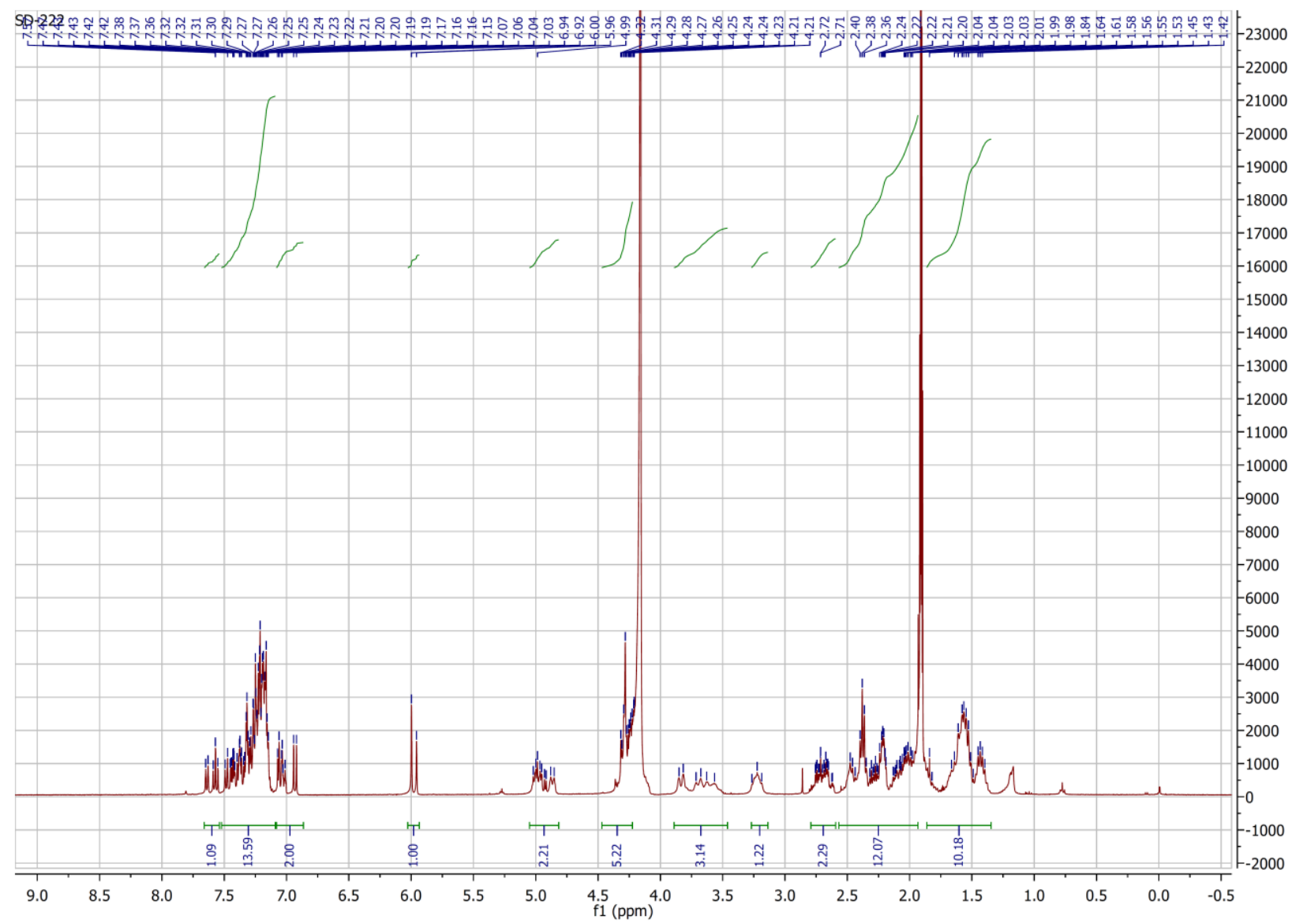


UPLC-MS analysis for compound 32.

\begin{tabular}{|llll|}
\hline & \multicolumn{2}{c|}{ S A M P L E } & I N F O R M A T I O N \\
\hline \hline Sample Name: & ZH-SD-222 & Acquired By: & System \\
Sample Type: & Unknown & Date Acquired: & 3/15/2019 2:51:07 PM EDT \\
Vial: & $1: E, 6$ & Acq. Method Set: & 10 to100\% Bin 10 min_Delay5min \\
Injection \#: & 1 & Date Processed: & 3/25/2019 1:23:08 PM EDT \\
Injection Volume: & $3.00 \mathrm{ul}$ & Processing Method: & Bruce \\
Run Time: & 10.0 Minutes & Channel Name: & 230.0nm \\
Sample Set Name: & 3 & Proc. Chnl. Descr.: & PDA Spectrum PDA 230.0 nm (PDf \\
\hline
\end{tabular}

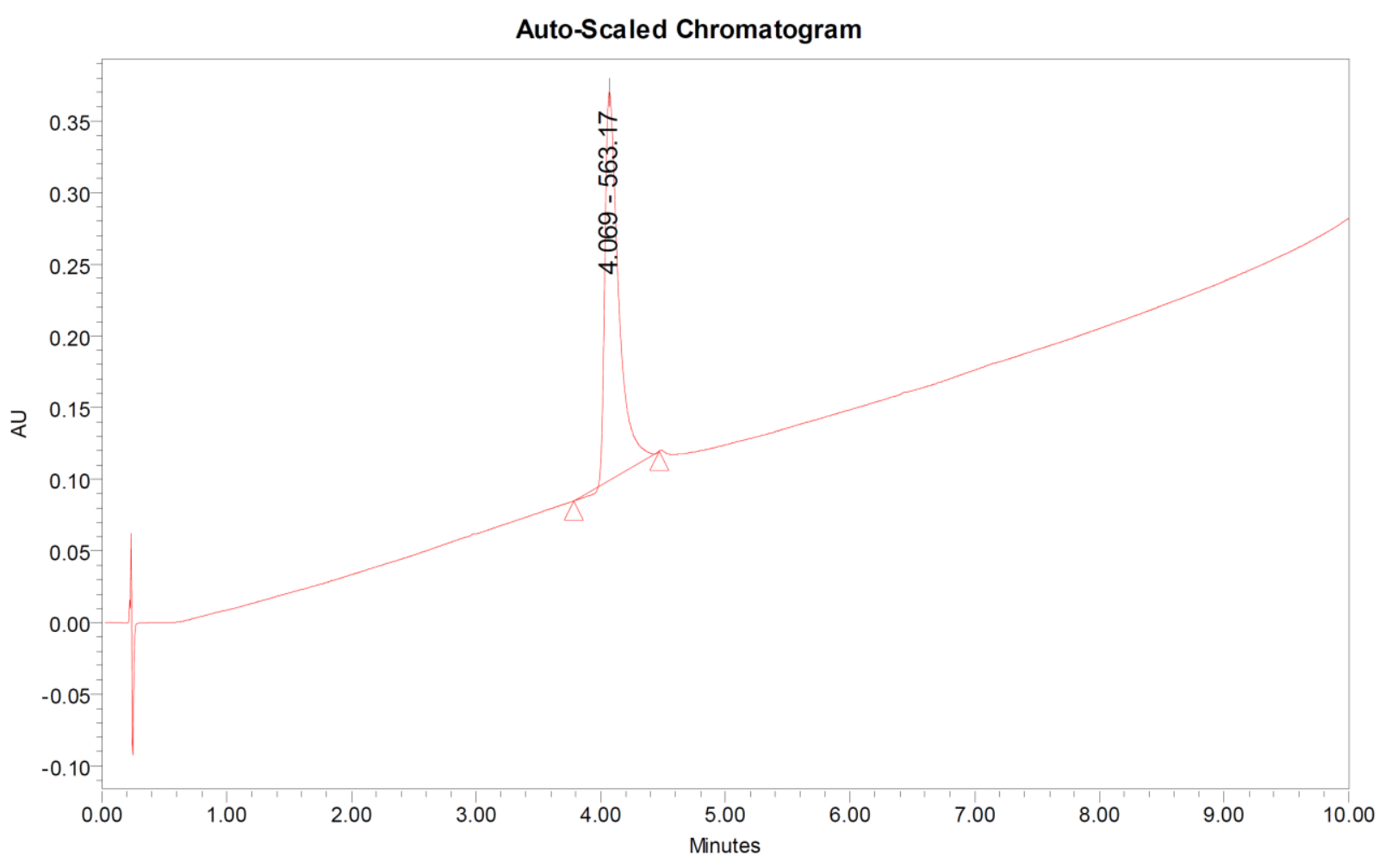

\begin{tabular}{|c|c|c|c|c|}
\hline \multicolumn{5}{|c|}{ Peak Results } \\
\hline & RT & Area & Height & $\%$ Area \\
\hline 1 & 4.069 & 2069216 & 270698 & 100.00 \\
\hline
\end{tabular}

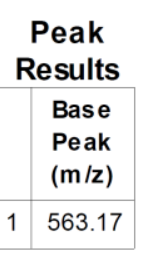




\section{${ }^{1} \mathrm{H}$ NMR for compound 33 .}

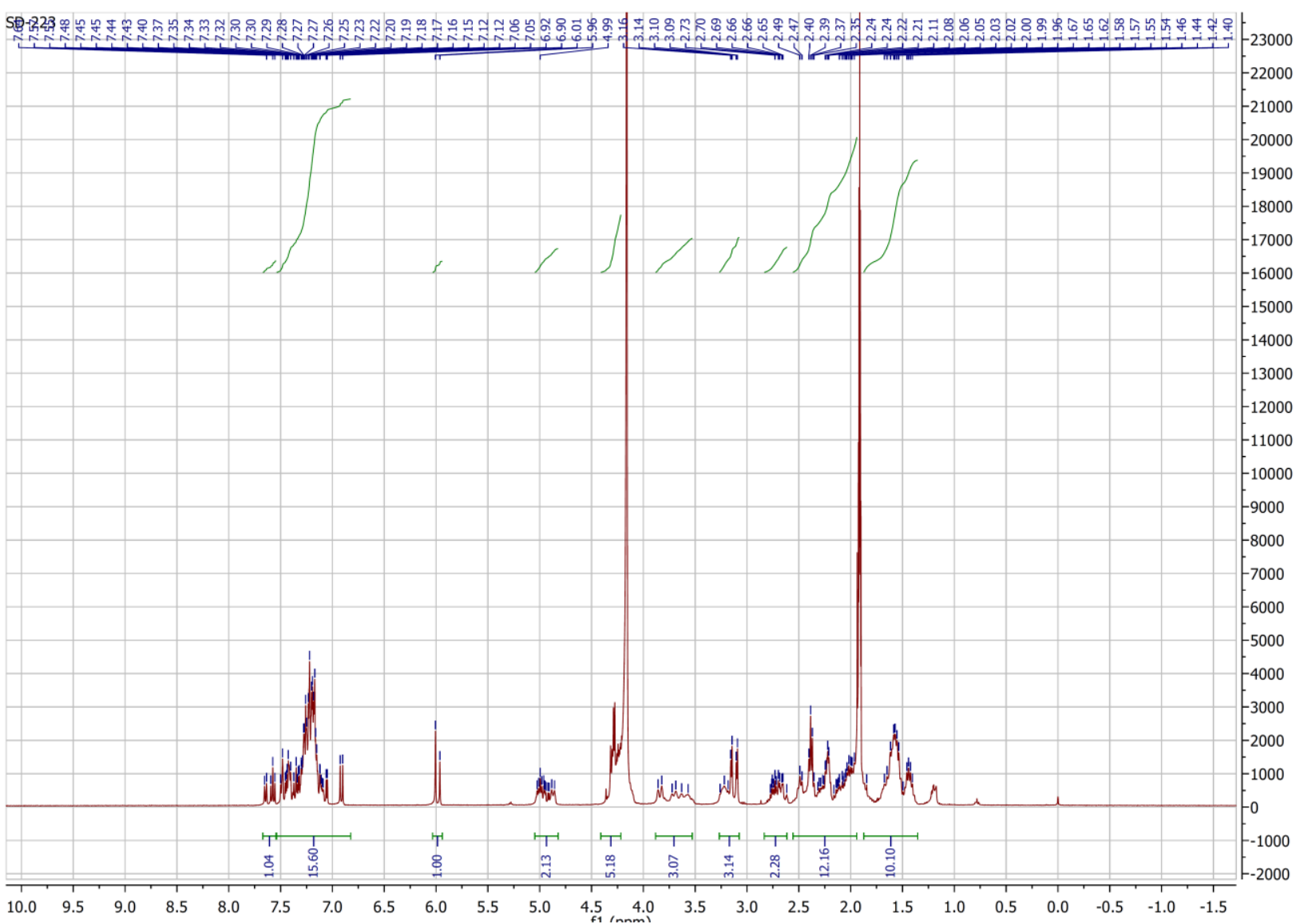


UPLC-MS analysis for compound 33.

\begin{tabular}{|llll|}
\hline & \multicolumn{2}{c|}{ S A M P L E } & I N F O R M A T I O N \\
\hline \hline Sample Name: & ZH-SD-223 & Acquired By: & System \\
Sample Type: & Unknown & Date Acquired: & 3/15/2019 3:42:59 PM EDT \\
Vial: & $1: E, 8$ & Acq. Method Set: & 10to100\% Bin 10 min_Delay5min \\
Injection \#: & 1 & Date Processed: & 3/25/2019 1:23:36 PM EDT \\
Injection Volume: & $3.00 \mathrm{ul}$ & Processing Method: & Bruce \\
Run Time: & 10.0 Minutes & Channel Name: & 230.0nm \\
Sample Set Name: & 3 & Proc. Chnl. Descr.: & PDA Spectrum PDA 230.0 nm (PDA \\
\hline
\end{tabular}

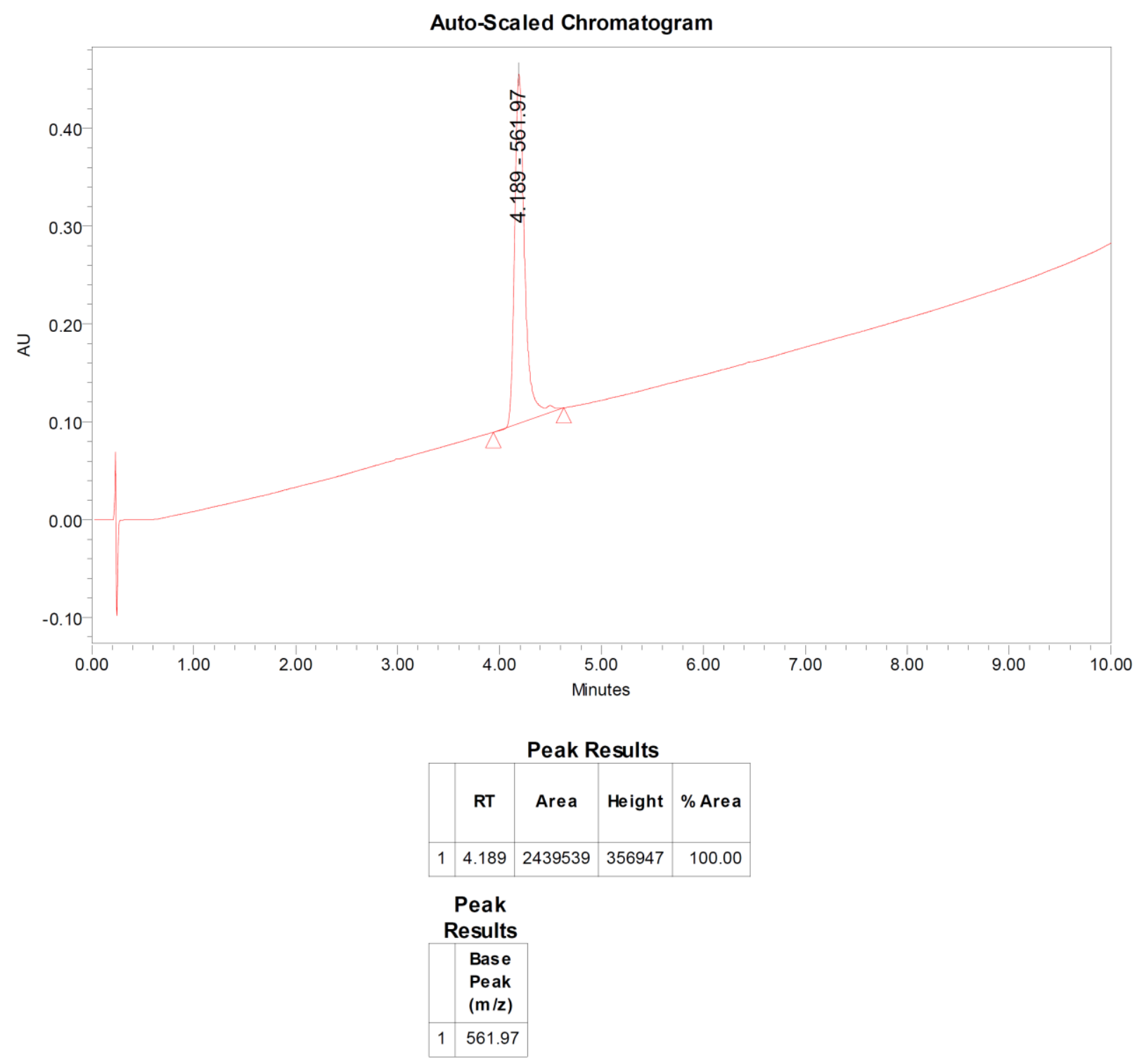


${ }^{1} \mathrm{H}$ NMR for compound 34 .

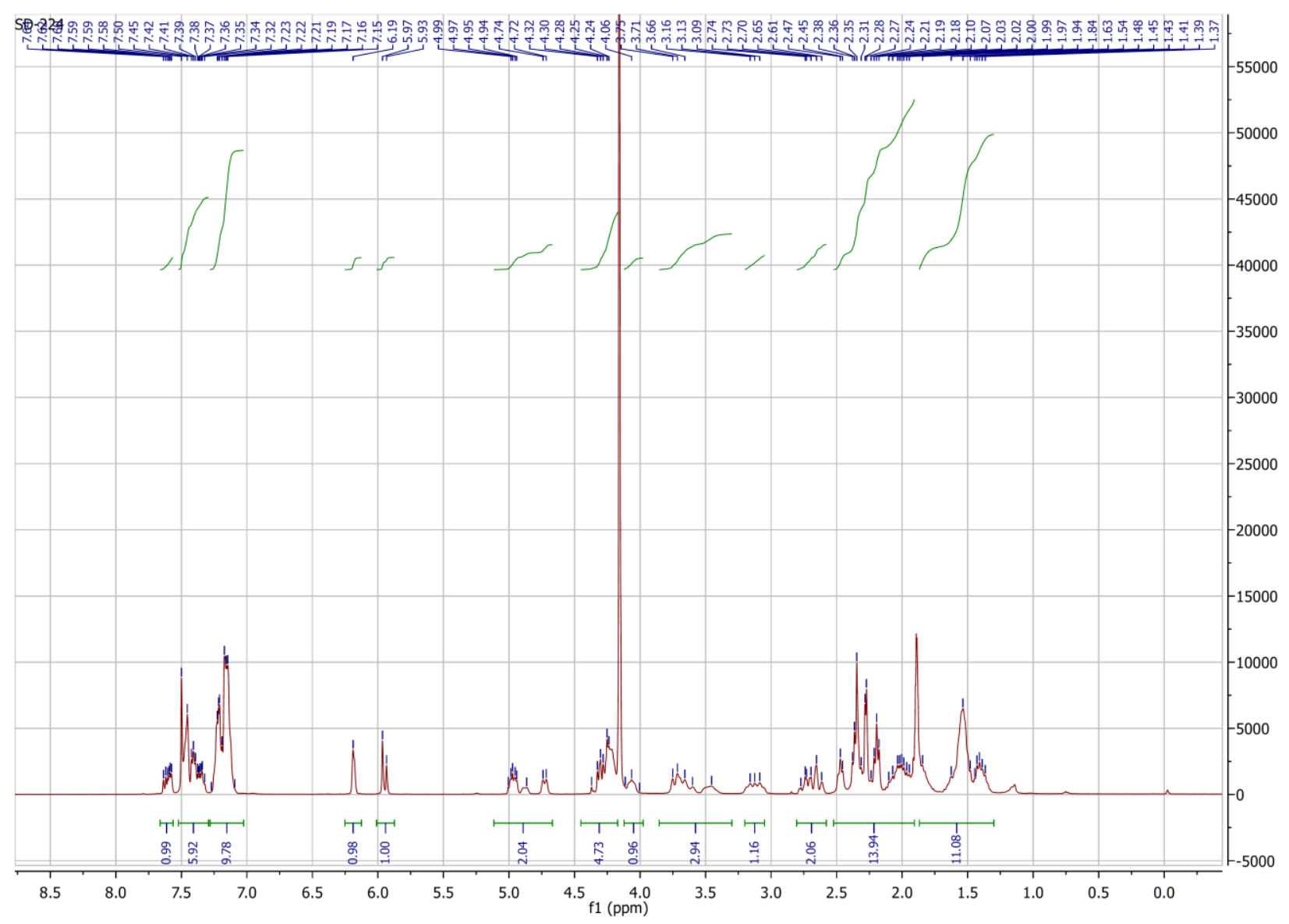


UPLC-MS analysis for compound 34.

\begin{tabular}{|c|c|c|c|}
\hline \multicolumn{2}{|r|}{ SAMPLE } & \multicolumn{2}{|c|}{ INFORMATION } \\
\hline $\begin{array}{l}\text { Sample Name: } \\
\text { Sample Type: }\end{array}$ & $\begin{array}{l}\text { ZH-SD-224 } \\
\text { Unknown }\end{array}$ & $\begin{array}{l}\text { Acquired By: } \\
\text { Date Acquired: }\end{array}$ & $\begin{array}{l}\text { System } \\
\text { 3/29/2019 10:15:55 AM EDT }\end{array}$ \\
\hline Vial: & $1: E, 6$ & Acq. Method Set: & 10to100\% Bin 10 \\
\hline $\begin{array}{l}\text { Injection \#: } \\
\text { Injection Volume: }\end{array}$ & $\begin{array}{l}1 \\
3.00 \mathrm{ul}\end{array}$ & $\begin{array}{l}\text { Date Processed: } \\
\text { Processing Method: }\end{array}$ & 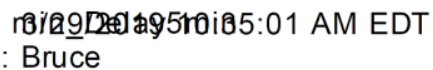 \\
\hline Run Time: & 10.0 Minutes & Channel Name: & $230.0 \mathrm{~nm}$ \\
\hline Sample Set Name & $: 111$ & Proc. Chnl. Descr.: & PDA Spectrum $(210-500) \mathrm{nm}$ \\
\hline
\end{tabular}

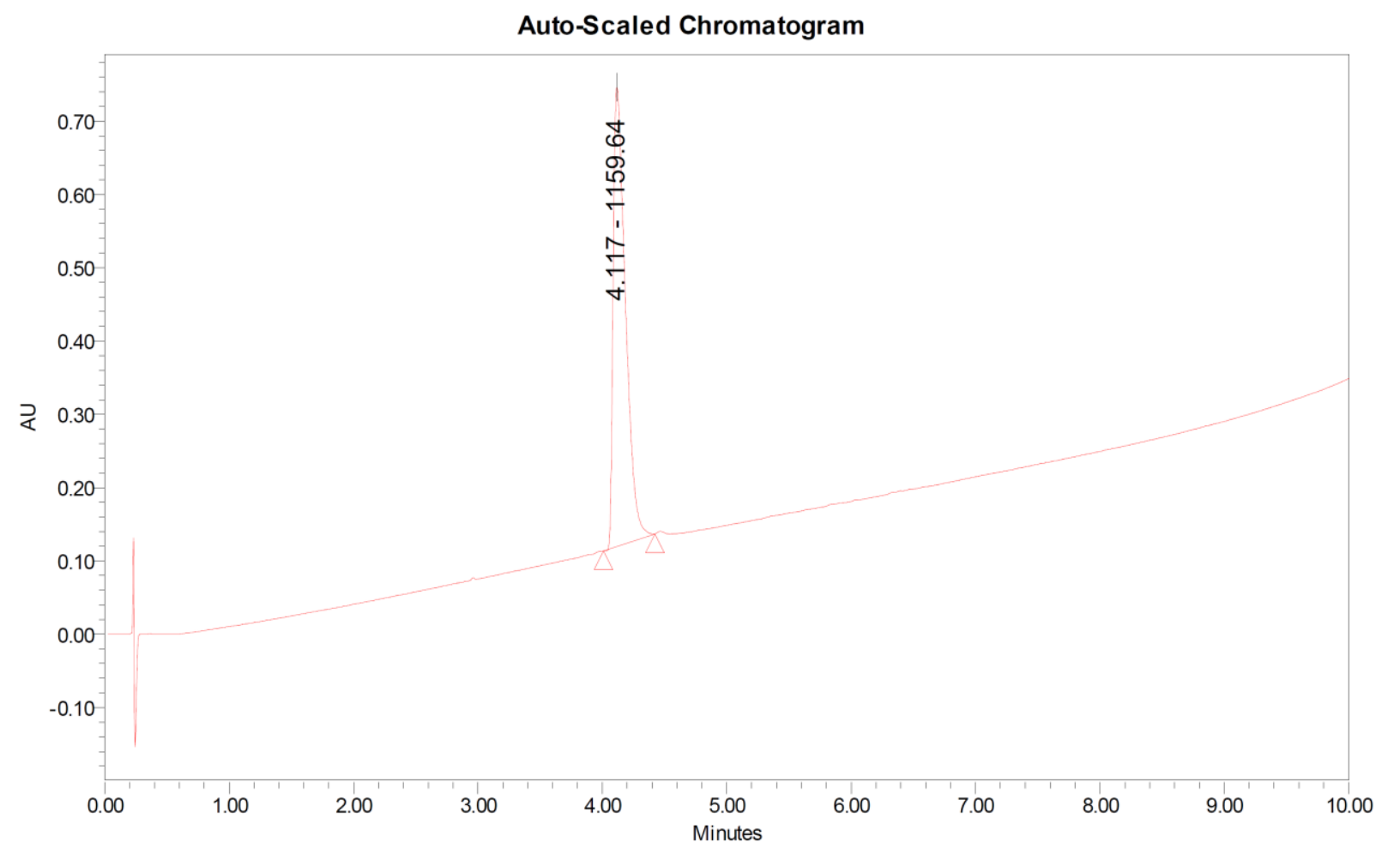

\begin{tabular}{|c|c|c|c|c|}
\hline \multicolumn{5}{|c|}{ Peak Results } \\
\hline & RT & Area & Height & $\%$ Area \\
\hline 1 & 4.117 & 4286274 & 626716 & 100.00 \\
\hline
\end{tabular}

\begin{tabular}{|c|c|}
\hline \multicolumn{2}{|c|}{$\begin{array}{c}\text { Peak } \\
\text { Results }\end{array}$} \\
\hline & $\begin{array}{l}\text { Base } \\
\text { Peak } \\
(\mathrm{m} / \mathrm{z})\end{array}$ \\
\hline & 1159.6 \\
\hline
\end{tabular}


${ }^{1} \mathrm{H}$ NMR for SD-36Me (35).

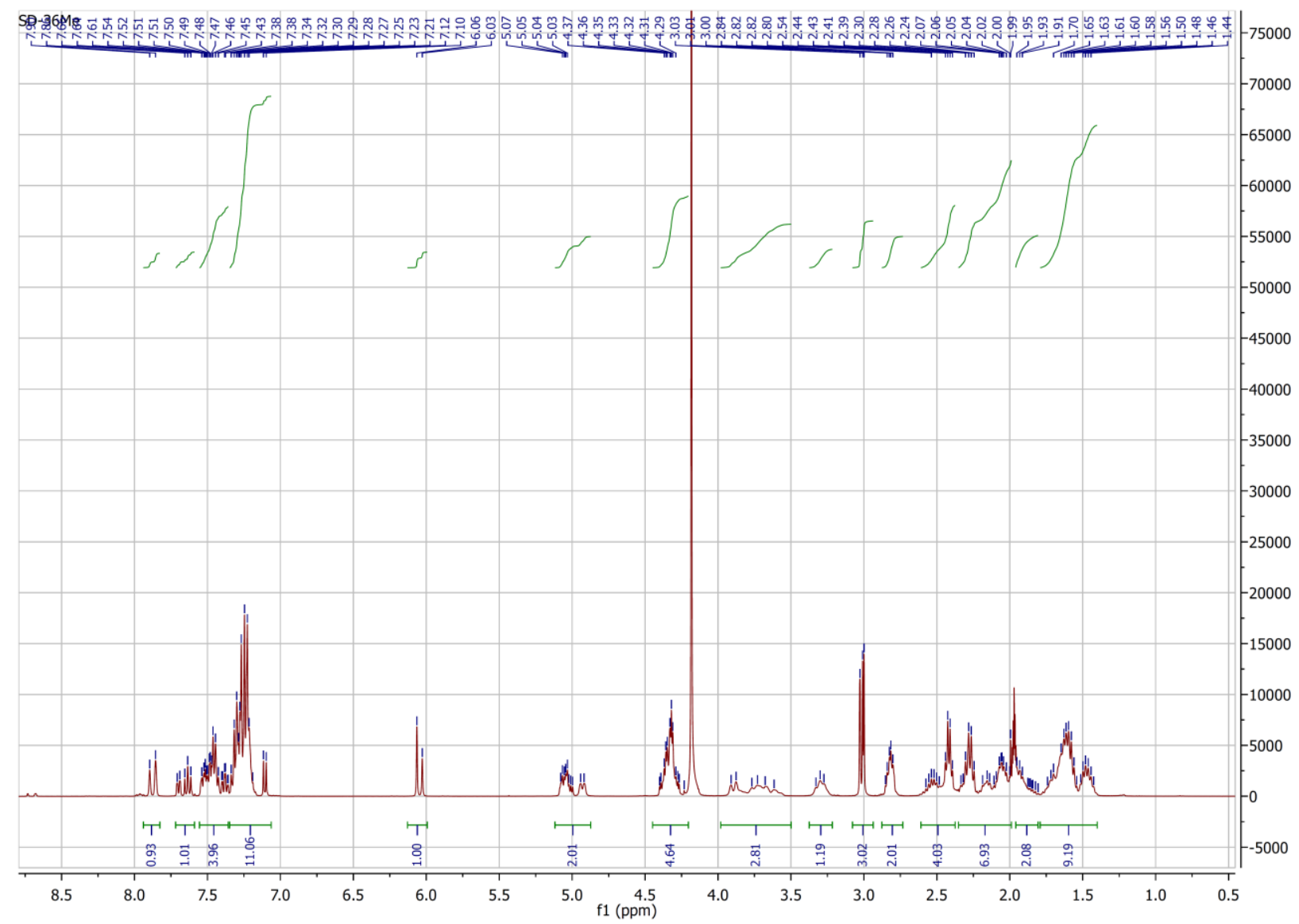


UPLC-MS analysis for SD-36Me (35).

\begin{tabular}{|c|c|c|c|}
\hline \multicolumn{4}{|c|}{ SAMPLE } \\
\hline Sample Name: & thesd-36mß-hplc & Acquired By. & System \\
\hline Sample Type: & Uthnown & Date Aoquired: & 8/1/20184:00:34PMEDT \\
\hline Vial: & $1: B, 8$ & Acc Method Set. & 10 to100\%Bin 10 min_Delay5min \\
\hline Irjection\#. & 1 & Date Processed: & 8/2/20182:04:05 PMEDT \\
\hline Irjection Volume: & $3.00 \mathrm{u}$ & Processing Method: & Bruce \\
\hline RnTime: & 10.0 Mnutes & Chamel Name: & $220.0 \mathrm{~mm}$ \\
\hline Sample Set Name: & 3 & Proc. Orn. Desar: & PDA SpectrumPDA $220.0 \mathrm{~m}$ (PDA Spectrum \\
\hline
\end{tabular}

AutoScaled Chromatogram

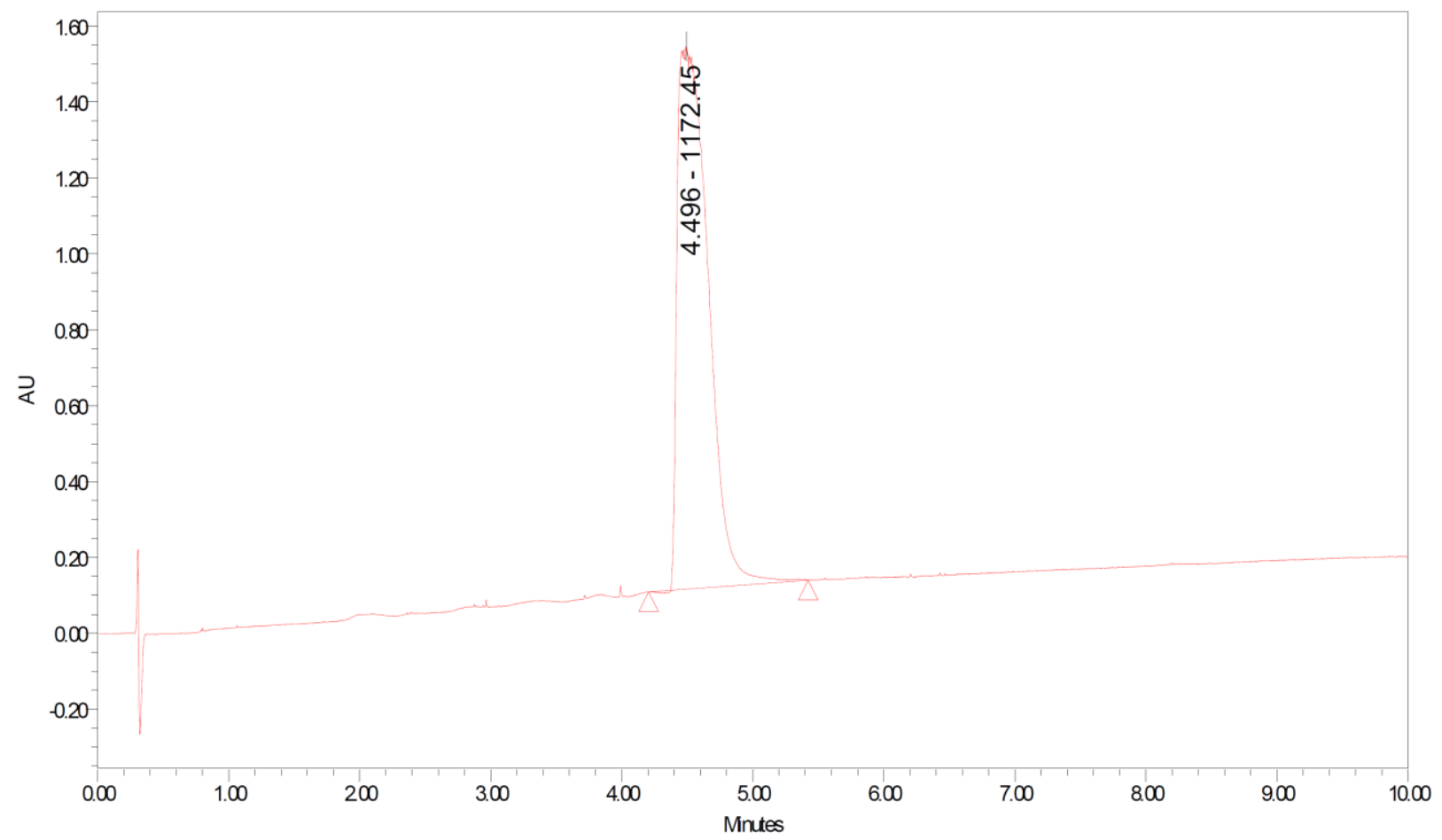

\section{PeakResults}

\begin{tabular}{|c|c|c|c|c|c|}
\hline & RT & Area & Height & $\%$ Area & $\begin{array}{c}\text { Bas } \\
\text { Peak } \\
\text { (m/z) }\end{array}$ \\
\hline 1 & 4.496 & 23457871 & 1430384 & 100.00 & 117245 \\
\hline
\end{tabular}

